\title{
The added value of high resolution in estimating the surface mass balance in southern Greenland
}

\author{
Willem Jan van de Berg ${ }^{1}$, Erik van Meijgaard ${ }^{2}$, and Lambertus H. van Ulft $^{2}$ \\ ${ }^{1}$ IMAU, Utrecht University, Utrecht, the Netherlands \\ ${ }^{2}$ KNMI, De Bilt, the Netherlands
}

Correspondence: Willem Jan van de Berg (w.j.vandeberg@uu.nl)

Received: 28 October 2019 - Discussion started: 10 December 2019

Accepted: 23 April 2020 - Published: 9 June 2020

\begin{abstract}
The polar version of the regional climate model RACMO2, version 2.3p1, is used to study the effect of model resolution on the simulated climate and surface mass balance (SMB) of south Greenland for the current climate (20072014). The model data at resolutions of $60,20,6.6$, and $2.2 \mathrm{~km}$ are intercompared and compared to SMB observations using three different data refinement methods: nearest neighbour, bilinear interpolation, and a statistical downscaling method utilising the local dependency of fields on elevation. Furthermore, it is estimated how the errors induced by model resolution compare to errors induced by the model physics and initialisation.

The results affirm earlier studies that SMB components which are tightly linked to elevation, like runoff, can be refined successfully, as soon as the ablation zone is reasonably well resolved in the source dataset. Precipitation fields are also highly elevation dependent, but precipitation has no systematic correlation with elevation, which inhibits statistical downscaling to work well. If refined component-wise, $20 \mathrm{~km}$ resolution model simulations can reproduce the SMB ablation observations almost as well as the finer-resolution model simulations. Nonetheless, statistical downscaling and regional climate modelling are complementary; the best results are obtained when high-resolution RACMO2 data are statistically refined. Model estimates in the accumulation zone do not benefit from statistical downscaling; hence, a resolution of about $20 \mathrm{~km}$ is sufficient to resolve the majority of the accumulation zone of the Greenland Ice Sheet with respect to the limited measurements we have.
\end{abstract}

Furthermore, we demonstrate that using RACMO2, a hydrostatic model, at $2.2 \mathrm{~km}$ resolution led to invalid results as topographic and synoptic vertical winds exceed $10 \mathrm{~m} \mathrm{~s}^{-1}$, which violates the hydrostatic model assumptions.

Finally, additional tests show that model resolution is as important as properly resolving spatial albedo patterns, correctly initialising the firn column, and uncertainties in the modelled precipitation and turbulent exchange.

\section{Introduction}

The Greenland Ice Sheet (GrIS) is the second largest ice sheet on Earth and in the most recent years the GrIS was the largest single contributor to global sea level rise (Vaughan et al., 2013; van den Broeke et al., 2016). The GrIS mass loss is partly due to enhanced glacial ice discharge, but most of the mass loss acceleration is caused by enhanced ablation, i.e. runoff of meltwater from snow and ice melt. It is projected that in the future enhanced ablation will increasingly negatively impact the mass balance of the GrIS (e.g. van Angelen et al., 2013; Fettweis et al., 2013).

Runoff and precipitation are the two primary components of the (climatological) surface mass balance (SMB), which includes internal accumulation by meltwater refreezing or retention. Undisputedly, the SMB depends strongly on the local topography. Precipitation fluxes generally decrease with elevation and latitude as the amount of atmospheric moisture is much smaller at lower temperatures. However, where topography blocks the atmospheric flow, precipitation is enhanced instead. Runoff increases with decreasing elevation, but it is not solely dependent on elevation as, for example, precipitation provides a negative feedback on runoff through enlarged meltwater refreezing capacity and mitigated response of the 


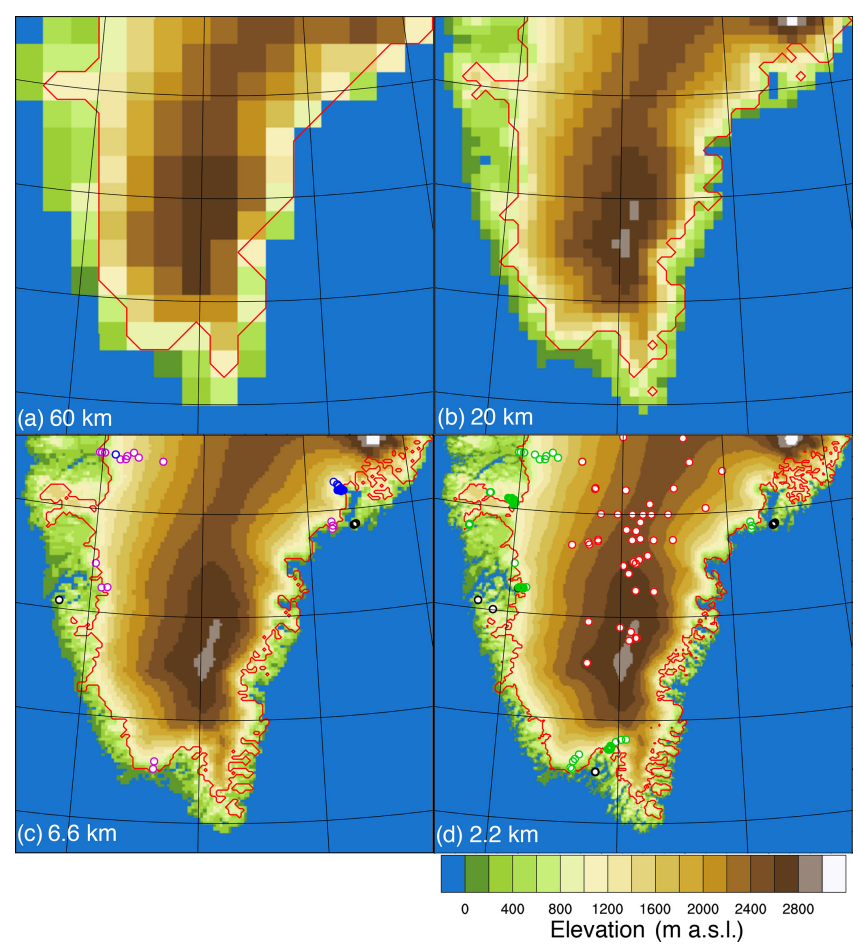

Figure 1. Model elevation and outline of glaciated areas (red) in the shared part of the domain for the four different model resolutions. In (c), locations of the excluded (black), single year (magenta), and summer (blue) time matched observations are drawn. In (d), locations of excluded (black) and multi-year ablation (green) and multiyear accumulation (red) observations are drawn.

melt-albedo feedback (e.g. Noël et al., 2015). It would be a good presumption that resolving the topography is a prerequisite to resolve the spatial patterns of the SMB, but this has not been proven yet. However, the topography of Greenland complicates the evaluation of such a presumption. Most of the interior ice sheet is rather flat and homogeneous (Fig. 1), because ice sheets level out elevation differences. Along the margins of Greenland, in contrast, the topography is rough and mountainous and the ice sheet and its adjacent glaciers are no longer fully covering the surface. Here, the horizontal length scales of the topography are small, $1 \mathrm{~km}$ or even less. In these marginal zones, the largest spatial gradients in SMB are expected.

Several methods exist to estimate the SMB of the GrIS (van den Broeke et al., 2017). Unfortunately, only in dry snow areas where the annual layering is preserved without internal accumulation, i.e. refreezing of percolating meltwater, can the SMB be measured by remote sensing. For that reason, ice-sheet-encompassing SMB estimates can thus only be derived with numerical models. Earth system models (ESMs) have made significant progress in including the complex physical processes that govern the atmosphere-glaciated surface exchange of mass and energy (e.g. Vizcaíno et al., 2013; van Kampenhout et al., 2019). However, current conven- tional computational budgets limit ESMs to resolutions of 0.5 or $1.0^{\circ}$, so south Greenland, for example, is resolved in comparable detail as shown in Fig. 1a. To overcome this limitation it is common practice to use regional climate models (RCMs), i.e. dynamical downscaling, in analysing the climate and SMB of the GrIS, and typically resolutions at 20 to $5.5 \mathrm{~km}$ resolution are used (e.g. Noël et al., 2015, 2018; Fettweis et al., 2017; Langen et al., 2017). The hydrostatic assumption used in these models inhibits a further refinement of the model grid, although some further refinement of the SMB can be archived by using fractional glacier masks (Fettweis et al., 2017). For simulations at higher resolutions, non-hydrostatic (regional) models are required. This type of model, however, has been primarily developed for the purpose of weather forecasting in the mid-latitudes, so most of them currently lack the required detailed description of the relevant surface processes of glaciated surfaces. Nonetheless, non-hydrostatic models like WRF, NHM-SMAP, and HARMONIE are increasingly applied for glaciated regions, e.g. by Hines and Bromwich (2008), Mottram et al. (2017), Niwano et al. (2018), and DuVivier and Cassano (2013), but due to their non-hydrostatic dynamical cores their computational costs are higher than those of hydrostatic models. Finally, SMB estimates up to the resolution of the latest digital elevation models (10 to $100 \mathrm{~m}$ ) can be generated using statistical downscaling, as presented by Noël et al. (2016). For Greenland, a refinement to $1 \mathrm{~km}$ provided the best trade-off between data sizes and additionally resolved patterns. However, this type of statistical downscaling can only add value if the downscaled fields correlate locally with topography.

With three available methods, i.e. ESMs, dynamical downscaling, and statistical downscaling, the question arises which (combination of) approach(es) provides the best estimate of local and integrated SMB of the GrIS and its peripheral glaciers. Are RCMs still required for the best possible SMB estimates or could statistical downscaling of ESMderived SMB provide equally good estimates? Furthermore, if RCMs still provide added value, what is the optimal resolution? For example, could a grid refinement of RCMs to kilometre scales provide superior results compared to all currently available methods? Finally, can we estimate for which resolution the approximations in model parameterisations and model initialisation become a source of error as important as model resolution?

In order to answer these questions, the polar version of the hydrostatic RCM RACMO2, version 2.3p1, has been run for south Greenland at four different resolutions: 60, 20, 6.6, and $2.2 \mathrm{~km}$. These simulations, with and without statistical downscaling, are analysed and compared to ablation and accumulation observations. The simulation at $2.2 \mathrm{~km}$ has been performed to investigate to which extent violating the assumptions made in RACMO2, i.e. hydrostatic atmospheric flow and that convective motion must be fully parameterised, deteriorate the model results. The results presented here, therefore, provide by no means any justification to apply a hy- 
drostatic model to resolutions below $5 \mathrm{~km}$ an operational basis. Furthermore, the effect of grid refining on the SMB is compared to the effect of parameter tuning and modelling choices. In this way, the performance of statistical downscaling compared to dynamical downscaling can be assessed and the sources of uncertainty and errors can be determined, hence providing directions for further model development and research.

This paper starts with a description of RACMO2, some specific new parameterisations applied here, and the observations used for evaluation. Next, the model results are analysed. First, statistical downscaling is applied to compare lowresolution RCM output with high-resolution output, followed by a comparison of modelled data with observations. Then, we discuss the drivers of the differences in the model outcome for the highest resolution, and finally the sensitivity of model outcome to modelling and parameterisation choices is investigated. The paper is finalised with a discussion and conclusions.

\section{Definitions, model, runs, statistical methods, and observations}

The climatological surface mass balance (SMB) is the local net mass gain or loss due to surface processes and internal accumulation, expressed in millimetres of water equivalent per year. For this study, we take the following components into account:

$\mathrm{SMB}=\operatorname{Prp}-\mathrm{SU}-\mathrm{RU}-\mathrm{ER}_{\mathrm{ds}}$,

where Prp, SU, RU, and $\mathrm{ER}_{\mathrm{ds}}$ are precipitation, sublimation including drifting snow sublimation, meltwater runoff, and erosion due to transport of drifting snow, respectively. Precipitation is the primary mass source; SU, RU, and $E_{\mathrm{ds}}$ are (predominantly) mass loss terms, and for these three components positive values imply a mass loss.

\subsection{RACMO2}

The polar version of the Regional Atmospheric Climate Model RACMO2 has been used for over a decade to investigate the climate and SMB of Greenland. In the model simulations presented here, version $2.3 \mathrm{p} 1$ is used, which consists of the hydrostatic dynamics of the RCM HIRLAM, version 5.0.6 (Undén et al., 2002) and the physics package of the ECMWF IFS model, version cy33r1 (ECWMF-IFS, 2009). Additionally, the polar version incorporates a multilayer snow model (Ettema et al., 2010), including grainsize-dependent albedo (Kuipers Munneke et al., 2011) and snow drift (Lenaerts et al., 2012), to represent the specific atmosphere-surface interactions on ice sheets. Meltwater percolation is modelled using the bucket method; if ice lenses are modelled in the firn pack, these are treated as permeable. Noël et al. (2015) present an evaluation of modelled climate and SMB of the Greenland Ice Sheet of model version 2.3p1.
The parameterisation of convection in the IFS physics uses an adapted version of the model presented by Tiedtke (1989). This module is used for all simulations, also for the run at $2.2 \mathrm{~km}$ resolution. The choice has drawbacks, as the parameterisation of convective clouds can start competing with the explicitly resolved mesoscale convective systems, reducing the quality of the model results. However, it should be kept in mind that this $2.2 \mathrm{~km}$ is run and discussed to show that RACMO2 is unsuitable for this resolution, irrespective of the quality of the modelled SMB. Furthermore, convective precipitation is of limited importance for the SMB of the GrIS, where convection is generally weak and limited to summertime.

Turbulent exchange of heat and moisture of the surface with the lowest model layer, which is at approximately $10 \mathrm{~m}$, are parameterised using Monin-Obukhov similarity theory (ECWMF-IFS, 2009). It assumes that, for neutral boundary layer conditions, the profiles of wind, dry static energy (heat), and specific humidity change logarithmically from their surface values to their values at the lowermost model level. The boundary layer is generally stable over glaciated surfaces, in which case the logarithmic profiles are corrected with stability profile functions of similar shape as proposed by Holtslag and de Bruin (1988). In the case of unstable conditions, the flux profiles of Dyer and Hicks (1970) are used. The transition height from near-surface laminar flow to turbulent flow and the effectiveness of turbulent exchange depends, among other factors, on the surface roughness length. For glaciated surfaces, the roughness length for momentum $\left(z_{0 \mathrm{~m}}\right)$ is set to 1 and $5 \mathrm{~mm}$ for snow-covered and bare-ice surfaces, respectively. The roughness length of heat $\left(z_{0 h}\right)$ and moisture $\left(z_{0 q}\right)$, a constant value for all other land surface types, is defined by the parameterisations of Andreas (1987) and Smeets and van den Broeke (2008b) for snow-covered and bare-ice surfaces, respectively. In these two parameterisations, $\left(z_{0 \mathrm{~h}}\right)$ and $\left(z_{0 \mathrm{q}}\right)$ decrease for increasing turbulence, hence limiting the increase in turbulent exchange. These parameterisations represent the flux-limiting effect of stratification on turbulent mixing while the surface drag (form drag) is less affected by stratification as it is also generated by the pressure fluctuations in the turbulent wake behind roughness elements (Smeets and van den Broeke, 2008b).

The reference polar version of RACMO2 employs the snow densification formulas as presented by Ligtenberg et al. (2011). These formulas, however, require precise a priori estimates of the local annual snowfall and temperature, which were not available prior to the simulations. Therefore, we initially explored an expression for creep of consolidated ice with cylindrical pores (Arthern et al., 2010, Eq. B1),

$\frac{\partial \rho}{\partial t}=k_{c}, \mathrm{~A} 10\left(\rho_{\mathrm{i}}-\rho\right) \exp \left[-\frac{E_{c, \mathrm{~A} 10}}{R T}\right] \sigma \frac{1}{r^{2}}$.

The variables used in this and the following equations are listed in Table 1. However, we were unable to tune this relation to match the modelled firn densities with snow density 
profiles from Antarctica (van den Broeke, 2008). We chose to focus on Antarctic firn cores for tuning, as in the Antarctic interior melt, which significantly alters the properties of firn cores and the densification process, is not occurring. Specifically, this equation fails to represent both the fast densification of low-density, fine-grained snow under very weak overburden pressure and the slower densification once the snow is denser and coarser grained while the overburden pressure is orders of magnitude bigger. However, densification partly depends on the recrystallisation of snow, which leads to a net growth of the crystals. Therefore, we modified Eq. (2) to the following empirical formula

$$
\frac{\partial \rho}{\partial t}=k(\rho) \exp \left[-\frac{E_{k}}{R T}\right] \sigma \frac{1}{r^{3}} \frac{\partial r^{3}}{\partial t},
$$

in which $k(\rho)$ is defined as

$$
\begin{array}{cc}
\rho<\rho_{\mathrm{s}}: & k(\rho)=k_{c}\left(\rho_{\mathrm{i}}-\rho\right)+k_{s}\left(\rho_{\mathrm{s}}-\rho\right)^{2} \\
\rho \geq \rho_{\mathrm{s}}: & k(\rho)=k_{c}\left(\rho_{\mathrm{i}}-\rho\right) .
\end{array}
$$

In Eq. (3), $k(\rho) \exp \left[-E_{k} / R T\right]$ represents the strength of the snow structure, $\sigma$ is the effective pressure applied to the snow, and $\left(1 / r^{3}\right)\left(\partial r^{3} / \partial t\right)$ provides a scaled measure of recrystallisation rate. The modelled evolution of the snow grain size $r$ includes dry and wet snow metamorphism and is discussed in Kuipers Munneke et al. (2011). Equations (3) and (4) were tuned using snow density profiles from Antarctica (van den Broeke, 2008) and are able to reproduce these density profiles almost as well as the model presented by Ligtenberg et al. (2011).

\subsection{Model simulations}

We performed simulations on four domains with resolutions of approximately $60,20,6.6$, and $2.2 \mathrm{~km}$, respectively. These four domains have a shared interior on which no boundary relaxation conditions were applied. This interior, on which we analyse the results, covers $900 \mathrm{~km} \times 900 \mathrm{~km}$, thus $15 \times 15$ and $405 \times 405$ grid boxes for the coarsest and finest model resolutions, respectively. The shared interior and the topography as resolved by the models are shown in Fig. 1. Around this interior, all domains include subsequently several rows of nonrelaxed grid points surrounded by the boundary relaxation zone. Runs at the four resolutions were carried out with a time step of $150,150,150 / 90$, and $60 \mathrm{~s}$. For the $6.6 \mathrm{~km}$ simulation, the smaller time step of $90 \mathrm{~s}$ was only used for months with high wind speeds, which causes the Lagrangian advection scheme to fail at processor sub-domain boundaries. In the $2.2 \mathrm{~km}$ simulation, this problem was mitigated by extending the shared-data rim around sub-domains from six to eight grid boxes. Simulations at all resolutions were carried out on the same vertical mesh with 40 model levels. The lowest model levels were at approximately 10,30 , and $90 \mathrm{~m}$ above the surface.

Simulations cover the period September 2006 to October 2014 and ECMWF Operational Analyses were used as boundary conditions. These boundaries and simulation period were chosen because Operational Analyses have a spatial resolution of $25 \mathrm{~km}$ (February 2006 to January 2010) and $16 \mathrm{~km}$ (February 2010 onwards) for this period, which allows us to drive the $2.2 \mathrm{~km} \mathrm{RACMO} 2$ run without intermediate RACMO2 simulation. Although this 11-fold grid refinement step is bigger than typically used for high-resolution studies, it was preferred here to a double-nesting approach, as the latter would inhibit comparing simulations covering similar domains. The runs have not been extended to more recent years as the last observations used here for evaluation (discussed below) were conducted in the summer of 2014.

Since no a priori outline is known of the modelled ablation, percolation, and dry snow zone, we chose to use a uniform initialisation of the snow model. All runs were initialised with a fresh snow layer of $50 \mathrm{~cm}$ in order to have, without long spin-up, good results in the ablation zone where perennial snow is absent. For the dry snow zone this initialisation is also deemed sufficient because it reproduces the thermal characteristics of a thick snow layer. However, in the percolation zone this relatively thin snow pack lacks refreezing capacity, especially if precipitation is low. This affects runoff estimates in the percolation zone as will be discussed later. Finally, a constant ice albedo of 0.42 - a typical bare-ice albedo value for the GrIS - is used, instead of MODIS-derived albedo as is used in Noël et al. (2015), in order to improve the comparability of the model results at various resolutions. The reference soot concentration is set to 0.10 ppmv, equivalent to the default value in RACMO2.1 and RACMO2.3p1 (van Angelen et al., 2012; Noël et al., 2015).

Unless stated differently, the first year of the simulation is excluded to reduce the effect of firn layer spin-up on the modelled SMB.

\subsection{Refinement methods}

Besides using RACMO2, which can be seen as using dynamical downscaling as a refinement method, three methods to refine output were tested: nearest-neighbour remapping, bilinear interpolation, and a form of statistical downscaling. We tested both downscaling of the modelled SMB and a component-wise downscaling of the SMB components in Eq. (1). All methods are applied to period-averaged accumulated quantities and not to daily accumulated SMB fields.

The SMB is only derived for ice sheet model grid points because outside this mask no valid estimates of SU, RU, and $\mathrm{ER}_{\mathrm{ds}}$ are provided. For nearest-neighbour estimates, we assume that $\mathrm{SU}, \mathrm{RU}$, and $\mathrm{ER}_{\mathrm{ds}}$ are zero outside the ice sheet. For bilinearly interpolated estimates, modelled fields of SU, $\mathrm{RU}$, and $\mathrm{ER}_{\mathrm{ds}}$ are extrapolated outside the ice sheet domain prior to interpolation. The extrapolation was done iteratively by assigning the average of eight surrounding grid boxes to unassigned grid boxes if at least three of these grid boxes have an assigned value. 
Table 1. List of variables in Eqs. (3) and (4).

\begin{tabular}{|c|c|c|c|c|}
\hline Symbol & & Value & Unit & Description \\
\hline$\rho$ & & & $\mathrm{kg} \mathrm{m}^{-3}$ & Snow density \\
\hline$\rho_{\mathrm{i}}$ & & 900 & $\mathrm{~kg} \mathrm{~m}^{-3}$ & Density of ice \\
\hline$\rho_{\mathrm{S}}$ & & 600 & $\mathrm{~kg} \mathrm{~m}^{-3}$ & Threshold density for fast snow compaction \\
\hline$E_{k}$ & & $1.7 \times 10^{4}$ & $\mathrm{~J} \mathrm{~mol}^{-1}$ & Activation energy \\
\hline$E_{c, \mathrm{~A} 10}$ & & $4.24 \times 10^{4}$ & $\mathrm{~J} \mathrm{~mol}^{-1}$ & Activation energy \\
\hline$k_{c, \mathrm{~A} 10}$ & $\begin{array}{l}9.2 \times 10^{-9} \\
3.7 \times 10^{-9}\end{array}$ & $\begin{array}{l}\rho \leq 550 \mathrm{~kg} \mathrm{~m}^{-3} \\
\rho>550 \mathrm{~kg} \mathrm{~m}^{-3}\end{array}$ & $\mathrm{~kg}^{-1} \mathrm{~m}^{3} \mathrm{~s}^{-1}$ & Compression constant \\
\hline$k_{c}$ & & $2.45 \times 10^{-2}$ & $\mathrm{~Pa}^{-1}$ & Compression constant \\
\hline$k_{s}$ & & $9.3 \times 10^{-4}$ & $\mathrm{~m}^{3} \mathrm{~kg}^{-1} \mathrm{~Pa}^{-1}$ & Compaction constant \\
\hline$r$ & & & $\mathrm{~m}$ & Effective grain size \\
\hline$R$ & & 8.314 & $\mathrm{~J} \mathrm{~mol}^{-1} \mathrm{~K}^{-1}$ & Gas constant \\
\hline$\sigma$ & & & $\mathrm{Pa}$ & Overburden pressure \\
\hline$t$ & & & s & Time \\
\hline$T$ & & & $\mathrm{~K}$ & Snow temperature \\
\hline
\end{tabular}

Statistical downscaling from a host domain to a target domain uses the local dependency on topography (Noël et al., 2016). Unlike Noël et al. (2016), no subsequent adjustment step, in which local differences in the bare-ice albedo of the coarse- and high-resolution grid are used to minimise the mean SMB bias, has been carried out. Here, the downscaling is set up in the following manner. On every point on the host domain the local regression of a property $(y)$ to elevation $(h)$ is derived using the eight surrounding grid points, thus $y(h)=y_{0}+h b$. This regression is only calculated if four or more of these nine grid points have valid data. For Prp, all grid points are valid; for $\mathrm{SMB}, \mathrm{SU}$, and $\mathrm{ER}_{\mathrm{ds}}$ only data points on the ice sheet are valid, and for RU, only ice sheet points with non-zero runoff are valid. Ice sheet points with zero RU are excluded, because otherwise the regression of RU to elevation would be underestimated. If the host point of interest has valid data, $y_{0}$ is chosen in such a way that $y(h)$ matches the modelled $y$ at the elevation of the grid point, otherwise $y_{0}$ is derived from the best fit. For RU, only negative values for $b$ are accepted, i.e. runoff decreases with altitude, and a positive $b$ is set to zero. Next, $y_{0}$ and $b$ are extrapolated to host grid points for which no regression could be derived. Finally, $y_{0}$ and $b$ are bilinearly interpolated to the target grid, and refined estimates are derived using the local target elevation.

\subsection{Observations}

The modelled SMBs are compared with the ablation observations collected by Machguth et al. (2016b) and the accumulation observations presented by Bales et al. (2001, 2009). From the various datasets, only observations on the common model domain with known elevations were used.

The observations provided by Machguth et al. (2016b) are used in three ways, with the abbreviated name.
1. (Sub)-annual and time matched (annual ablation). Most of the ablation observations are precisely dated, so the ablation observations covering parts of the period between September 2006 and October 2014 are compared with model estimates for matching time periods. A total of 128 observations at 40 sites fulfilled these criteria; 108 of them were annual ablation observations, one was accumulated ablation of 2 years, and 19 were summer observations. These locations are shown in Fig. 1c. The observations left out are on Mittivakket near Tasiilaq and Qasigiannguit glacier near Nuuk, both because the observations are too far away from glaciated points in the 6.6 and $2.2 \mathrm{~km}$ simulations.

2. Averaged and time matched (period ablation). In order to reduce the possible impact of misrepresented temporal variability, the 128 observations at those 40 sites were averaged into 40 annual SMB estimates. The model estimates are again derived using the time period covered by these averaged annual SMB estimates.

3. Averaged (average ablation). Finally, as the short period for which RACMO2 is run excludes many observations, averaged modelled SMBs for October 2007 to September 2014 are compared to all available ablation observations, hence neglecting the interannual and decadal variability of SMB. For this purpose, separate records of ablation observations for a site were averaged into a single average per station, leading to 106 ablation estimates. Sites with only winter or summer balances were excluded. The locations of the multi-year mean ablation and accumulation observations are shown in Fig. 1d. Observations within the model domain but well outside the ice sheet masks at one of the resolutions were also excluded. These observations are shown in Fig. 1d as well. 


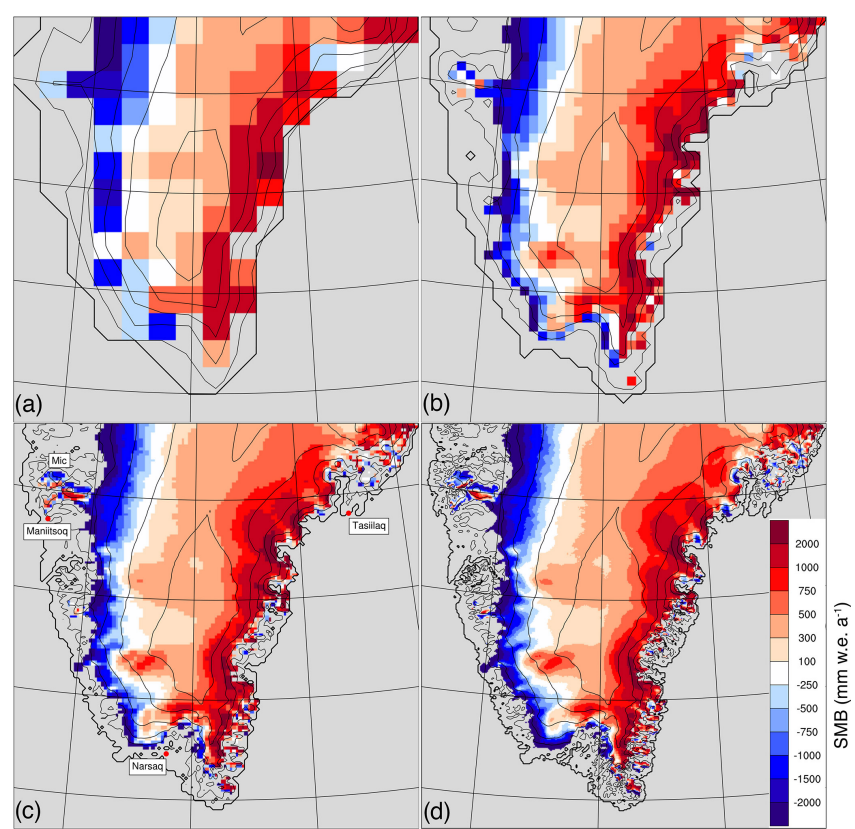

Figure 2. Annual mean SMB (mmw.e. $\mathrm{a}^{-1}$ ) for the period October 2007 till September 2014 derived with RACMO2 with a resolution of (a) 60 , (b) 20 , (c) 6.6 , and (d) $2.2 \mathrm{~km}$. Grid points outside the ice sheet mask are grey. In (c), Mic is used as an abbreviation for the Maniitsoq ice cap.

The accumulation observations, of which a considerable number was carried out well before 2006, are only used in the evaluation of the averaged modelled SMB for the full 7-year period from October 2007 to September 2014. Furthermore, accumulation observations with an elevation deviating more than $25 \mathrm{~m}$ from the Greenland Ice Mapping Project (GIMP, Howat et al., 2014) elevation were excluded as such a big elevation deviation for sites at the flat interior ice sheet indicate a location error.

\section{Results}

\subsection{Modelled SMB on various resolutions}

Not surprisingly, the main characteristics of the GrIS SMB (Fig. 2) show up in all resolutions, i.e. high accumulation along the eastern coast and an ablation zone along the western margin. However, finer structures start to emerge with increasing resolution, for example, wavy patterns in the precipitation field across topographic promontories, the windward and leeward SMB patterns over Maniitsoq ice cap (Fig. 2c), and the narrow ablation zones in the southern tip and along the east coast of Greenland. The differences between the modelled SMB field derived on the 2.2 and $6.6 \mathrm{~km}$ resolved grids seem minor but are significant at some locations, for example, west of Tasiilaq and north of Narsaq (Fig. 2c).
The spatially integrated SMB for this part of Greenland varies with model resolution (Table 2). The low- and medium-resolution runs have an integrated SMB of about $70 \mathrm{Gt} \mathrm{a}^{-1}$, but the $2.2 \mathrm{~km}$ resolution run deviates with an integrated SMB of $47 \mathrm{Gt} \mathrm{a}^{-1}$. Apart from runoff, which slightly increases with resolution, however, no large change in the mean value of the different SMB components is found. Precipitation is rather similar for all resolutions, and although higher extremes are modelled for fine model resolutions, the standard deviation remains similar for all resolutions except for the $60 \mathrm{~km}$ resolution run. Up to $6.6 \mathrm{~km}$ resolution, the mean precipitation increases due to grid refining because resolving the topography induces concentration of precipitation on the ice sheet, which is higher than the surrounding areas, instead of around it. The decrease in mean precipitation for the $2.2 \mathrm{~km}$ resolution run will be discussed in detail in Sect. 3.4. Sublimation is more than 1 order of magnitude smaller than precipitation and runoff. Mass loss by sublimation increases with resolution; at low resolutions the high sublimation rates due to the katabatic outflow of cold and dry air are not well modelled (not shown). The export of snow from the ice sheet by snow drift divergence is negligible at all resolutions. However, regional transport of snow becomes increasingly important at finer resolutions as the standard deviation of local mass changes increases by a factor of 2 for each 3-fold increase in model resolution.

\subsection{Statistical downscaling versus dynamical downscaling}

Before discussing the comparison of the modelled SMB with observations, we analyse to which extent the SMB and its contributing components can be sensibly refined. This analysis is done for all six possible simulation pairs; results are discussed in detail for the downscaling of $60 \mathrm{~km}$ data to $6.6 \mathrm{~km}$ only. We focus on precipitation and runoff, because these two processes largely determine the SMB.

\subsubsection{Precipitation}

Figure 3 shows the results of refining precipitation fields from 60 to $6.6 \mathrm{~km}$ resolution. At $60 \mathrm{~km}$ resolution (Fig. 3a), the main characteristics of the precipitation distribution over Greenland are resolved. The eastern coast is wetter than the western coast, the higher interior is relatively dry, and a precipitation shadow is located north of the Maniitsoq ice cap (Fig. 2c). As the model grids of 6.6 and $60 \mathrm{~km}$ align perfectly by design, the nearest-neighbour interpolated precipitation field equals Fig. 3a. Bilinear interpolation of this field to $6.6 \mathrm{~km}$ resolution (Fig. 3b) gives a smoother representation of the latter but does not contain additional information. Although the precipitation might seem to depend on elevation, applying statistical downscaling gives very similar results (Fig. 3c), because the correlation between precipitation and elevation is weak where the variability in pre- 
Table 2. Mean and spatial variability of the annual SMB and its components in the investigated region in south Greenland. All values are in millimetres of water equivalent per year. Additionally, spatially integrated mean SMB is given in gigatonnes per year.

\begin{tabular}{lrrrrrrr}
\hline Resolution & $\begin{array}{c}\text { Area } \\
10^{3} \mathrm{~km}^{2}\end{array}$ & \multicolumn{2}{c}{ SMB } & \multicolumn{2}{c}{$\begin{array}{c}\text { Prp } \\
\text { mean/SD; mm w.e. } \mathrm{a}^{-1}\end{array}$} & $\begin{array}{c}\text { SU } \\
\text { RU }\end{array}$ & $\mathrm{ER}_{\mathrm{ds}}$ \\
\hline $60 \mathrm{~km}$ & 317.1 & 64 & $203 / 911$ & $836 / 825$ & $34 / 30$ & $598 / 863$ & $1.1 / 4$ \\
$20 \mathrm{~km}$ & 316.3 & 75 & $237 / 956$ & $848 / 877$ & $47 / 40$ & $562 / 889$ & $1.2 / 8$ \\
$6.6 \mathrm{~km}$ & 318.4 & 71 & $223 / 1016$ & $884 / 904$ & $55 / 49$ & $584 / 962$ & $1.4 / 16$ \\
$2.2 \mathrm{~km}$ & 319.7 & 47 & $148 / 1056$ & $836 / 872$ & $54 / 53$ & $633 / 1061$ & $1.6 / 31$ \\
\hline
\end{tabular}

cipitation is highest. In general, statistical downscaling provides lower estimates for (relatively) high-altitude locations and higher estimates for low-altitude locations (Fig. 3f). Statistical downscaling also enhances the precipitation shadow north of the Maniitsoq ice cap. As a side note, precipitation estimates over the ocean, well away from Greenland, and derived with statistical downscaling deviate strongly as they are extrapolated from coastal precipitation rates since the statistical downscaling procedures fall short away from Greenland in absence of topographic variations.

However, all refining methods fail to reproduce the modelled precipitation patterns at $6.6 \mathrm{~km}$ resolution (Fig. 3d). At this resolution, along-coast variability is modelled: the windward side of promontories face high precipitation rates, while the leeward side of these promontories are much drier. These patterns are not reconstructed at all by statistical downscaling, and the differences between estimated (Fig. 3c) and modelled precipitation (Fig. 3d) are very substantial (Fig. 3e).

\subsubsection{Runoff}

At $60 \mathrm{~km}$ resolution (Fig. 4a) a wide runoff zone is modelled for West Greenland and narrower zones for south and East Greenland. These zones are wider than modelled by Noël et al. (2015); 2006-2014 were relatively warm years. The additional runoff in the percolation zone is not buffered by refreezing since the firn layer had no time to build up in the simulations presented here. However, runoff estimates along the margins are robust since only winter snow is present every spring; hence the spin-up of the snow and ice pack is short. As for precipitation, a bilinear interpolation of the runoff fields to $6.6 \mathrm{~km}$ (Fig. 4b) is a smoothed version of the $60 \mathrm{~km}$ field. Note that no high runoff values are introduced along the margin. These higher runoff values are introduced if runoff is refined using statistical downscaling (Fig. $4 \mathrm{c}$ and f). At $60 \mathrm{~km}$, maximum runoff estimates up to $2 \mathrm{mw}$.e. $\mathrm{a}^{-1}$ are modelled, but with statistical downscaling the maximum runoff estimates increase to over $3 \mathrm{mw}$ w.e. $\mathrm{a}^{-1}$. Higher runoff estimates are also introduced along the southern and eastern margins of the GrIS. Away from the ice sheet margin, statistical downscaling reduces the runoff due to the concave ice sheet topography. Due to the north-south orientation of the ice sheet, this introduces a striped difference pattern between linearly and statistically downscaled runoff (Fig. 4f). Numerical artefacts arise near the divide of the GrIS (Fig. 4c). Here, the correlation of runoff to elevation decreases, leading to negligible but incorrect patterns.

Comparing the downscaled patterns with the modelled runoff at $6.6 \mathrm{~km}$ resolution (Fig. $4 \mathrm{~d}$ ), statistical downscaling brings the estimate closer to the $6.6 \mathrm{~km}$ resolution runoff field compared to the bilinear interpolation but still lacks the high runoff values along the ice sheet margin. These high runoff rates occur because at lower elevation ice is increasingly exposed during the summer; more summer precipitation falls as rain, eliminating the mitigating effect of precipitation on melt; and warm tundra air can flow to some extent onto the ice sheet. All these processes are not modelled at $60 \mathrm{~km}$ resolution; hence the refined product fails to reproduce the large runoff gradient near the ice sheet margin. Nevertheless, statistical downscaling provides much better runoff estimates than bilinear interpolation of fields. Note that this difference is not due to variations in the ice albedo, as a constant albedo is used. In reality the albedo varies greatly from place to place.

\subsubsection{Statistical evaluation}

Analysis of the refining techniques using Taylor diagrams (Fig. 5) and the RMSD (Table 3) provides a quantitative assessment of the expected ability of different refining techniques to reproduce spatial SMB patterns. The horizontal axis in Fig. 5 displays the fraction of the true high-resolution model variability that is captured by the low-resolution model, while the vertical axis displays the amount of erroneous variability contained in the low-resolution model results. If a dataset matches perfectly with the reference dataset - excluding systematic biases - the normalised true and erroneous variability are one and zero, respectively. Therefore, this point on the $x$ axis has the label "REF". A dataset with similar variability as the reference dataset will be drawn on the dashed circle; if the variability is underestimated, points will be displayed closer to the $(0,0)$ point. Figure 5a shows the reproduced variability of the SMB and its components for the three investigated techniques for refining from 60 to $6.6 \mathrm{~km}$ resolution. Crude nearest-neighbour interpolated fields are also assessed in this figure in order to quantify if bilinear interpolation is better than no efforts at all. For 

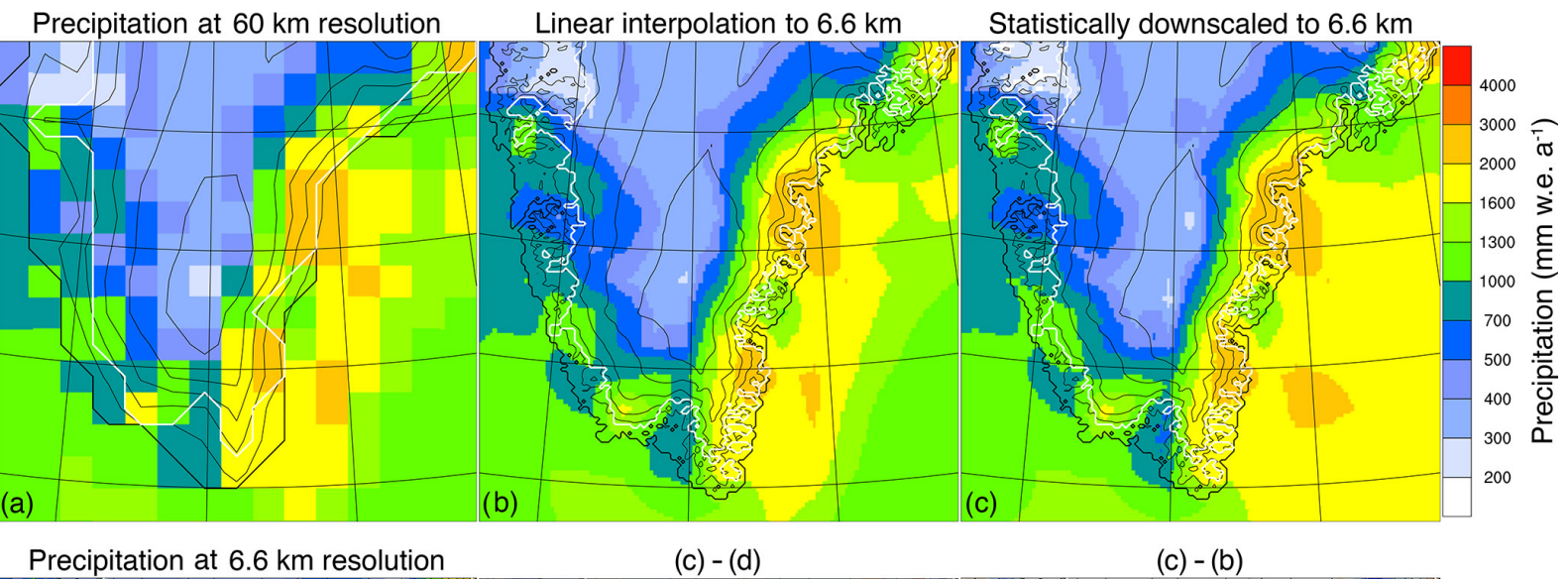

(b)

(c) - (d)
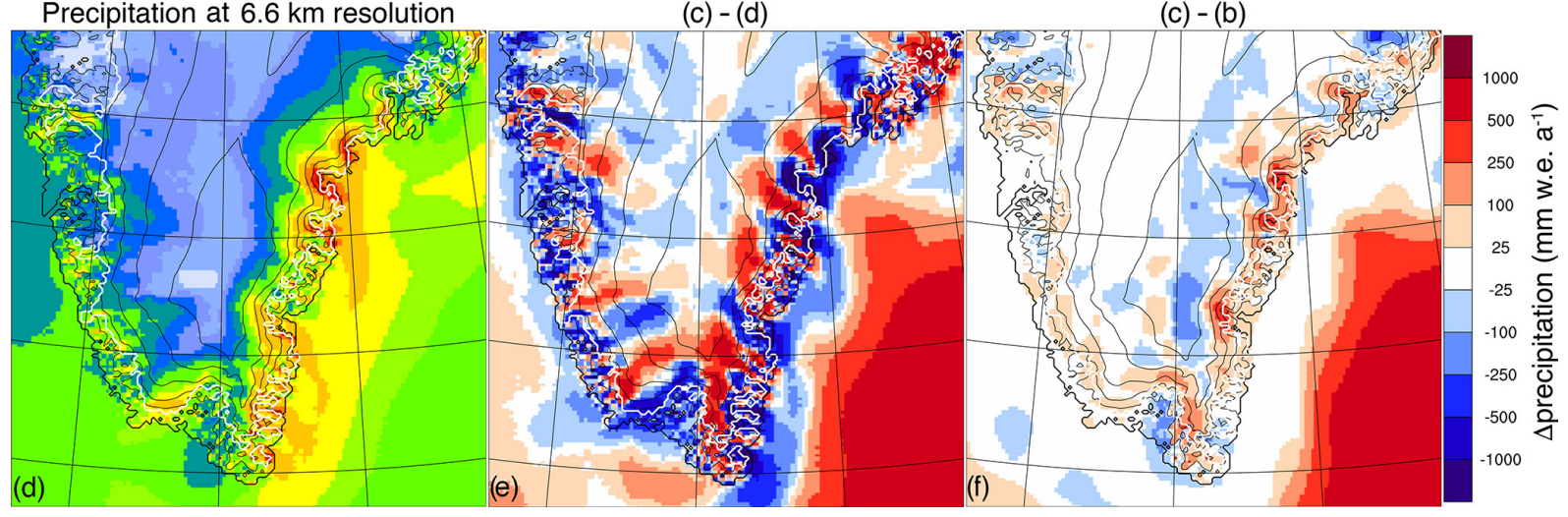

Figure 3. Results from refining precipitation from $60 \mathrm{~km}$ resolution to $6.6 \mathrm{~km}$ resolution. (a) Modelled precipitation at $60 \mathrm{~km}$ resolution. (b) Bilinear interpolated precipitation. (c) Statistically downscaled precipitation using local regression to elevation. (d) Modelled precipitation at $6.6 \mathrm{~km}$ resolution. (e) Difference between statistically downscaled (c) and modelled (d) precipitation. (f) Difference between statistically downscaled (c) and bilinear interpolated (b) precipitation. The white line marks the ice sheet margin.

precipitation, bilinear interpolation removes spurious patterns since the amount of incorrect information decreases, but bilinear interpolation does not add true model signal. Statistical downscaling adds some true model signal and provides, therefore, a better estimate of the modelled fields at $6.6 \mathrm{~km}$, but this improvement in the representation is small. For runoff, statistical downscaling provides the best estimate even though bilinear interpolation also improves the representation of modelled runoff estimate. The statistical downscaling removes a significant amount of the incorrect deviation and adds a significant amount of true modelled variability. As a result, the refined runoff field correlates strongly with the modelled fields at $6.6 \mathrm{~km}$ resolution.

For the other SMB components, the results of the refinement are not as good as for runoff. The modelled sublimation patterns at $60 \mathrm{~km}$ resolution show far less absolute variability than the modelled sublimation at $6.6 \mathrm{~km}$, and this variability is not added by statistical downscaling (Fig. 5a, green dots; Fig. S1 in the Supplement). Statistical downscaling of the sublimation modelled at $60 \mathrm{~km}$ does also not reduce the general underestimation of sublimation compared to the $6.6 \mathrm{~km}$ run (Table 2). Sublimation fields obtained with bilinear interpolation or statistical downscaling are thus qualitatively
Table 3. Root-mean-square differences (RMSDs, mmw.e. $\mathrm{a}^{-1}$ ) of bilinear (bl) and statistically downscaled (sd) variables for all resolution combinations. SMBc denotes component-wise processed SMB.

\begin{tabular}{lrrrrr}
\hline $\begin{array}{l}\text { Resolution } \\
\text { Increase factor }\end{array}$ & $\begin{array}{r}\text { SMB } \\
\text { bl/sd }\end{array}$ & $\begin{array}{r}\text { SMBc } \\
\text { bl/sd }\end{array}$ & $\begin{array}{r}\text { Prp } \\
\text { bl/sd }\end{array}$ & $\begin{array}{r}\text { RU } \\
\text { bl/ sd }\end{array}$ \\
\hline 60 to $20 \mathrm{~km}$ & 3 & $487 / 429$ & $472 / 404$ & $306 / 296$ & $345 / 185$ \\
20 to $6.6 \mathrm{~km}$ & 3 & $383 / 342$ & $367 / 318$ & $224 / 219$ & $244 / 147$ \\
6.6 to $2.2 \mathrm{~km}$ & 3 & $297 / 286$ & $288 / 270$ & $163 / 169$ & $190 / 144$ \\
\hline 60 to $6.6 \mathrm{~km}$ & 9 & $587 / 518$ & $573 / 488$ & $358 / 343$ & $443 / 250$ \\
20 to $2.2 \mathrm{~km}$ & 9 & $481 / 436$ & $461 / 413$ & $254 / 256$ & $342 / 234$ \\
\hline 60 to $2.2 \mathrm{~km}$ & 27 & $650 / 562$ & $636 / 519$ & $350 / 336$ & $539 / 324$ \\
\hline
\end{tabular}

not much better than sublimation fields produced by crude nearest-neighbour remapping. This is even more the case for snow drift divergence (Fig. 5a, grey dots; Fig. S2). Patterns at $60 \mathrm{~km}$ resolution have significantly less variability than patterns at $6.6 \mathrm{~km}$ resolution and lack the ability to reproduce any of the patterns at $6.6 \mathrm{~km}$ resolution. Hence, refining makes little sense. However, since snow drift divergence is 


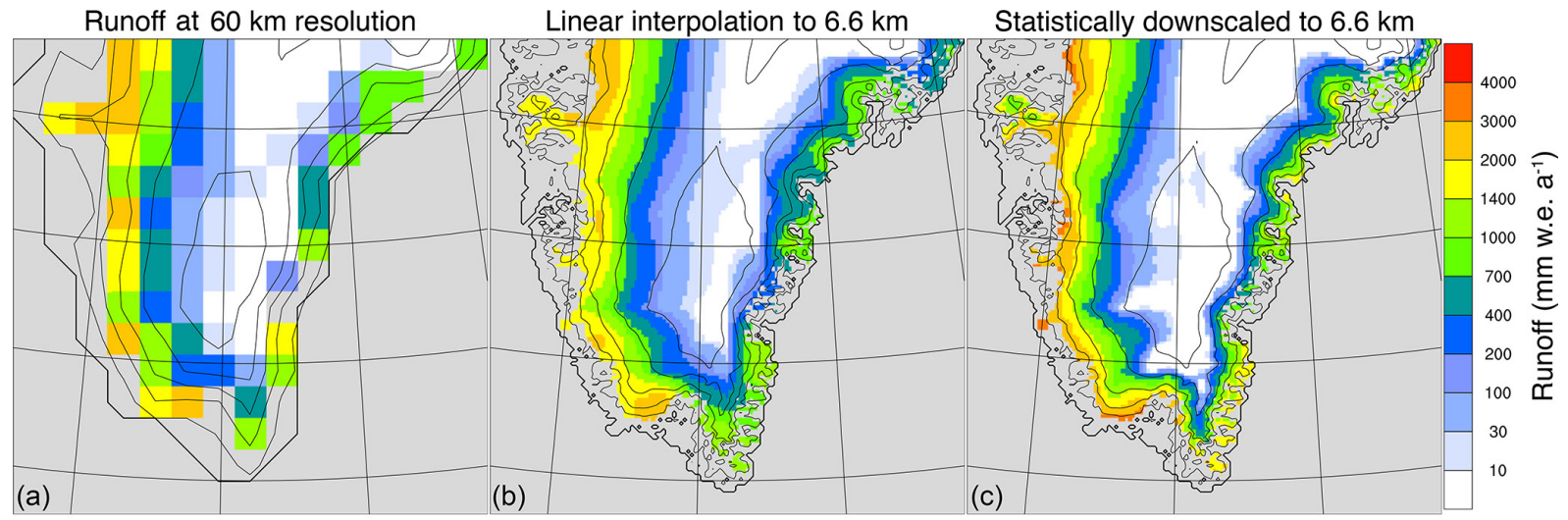

\section{Runoff at $6.6 \mathrm{~km}$ resolution}

(c) $-(d)$

(c) $-(b)$

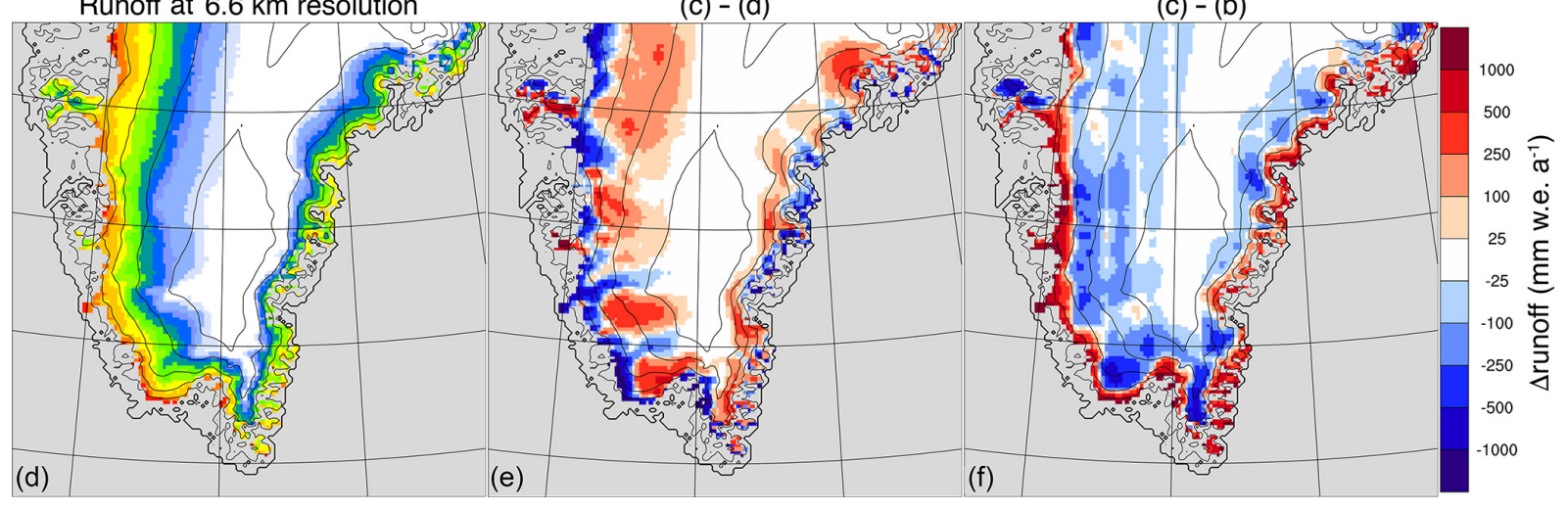

Figure 4. Results from refining runoff from $60 \mathrm{~km}$ resolution to $6.6 \mathrm{~km}$ resolution. (a) Modelled runoff at $60 \mathrm{~km}$ resolution. (b) Bilinear interpolated runoff. (c) Statistically downscaled runoff using local regression to elevation. (d) Modelled runoff at $6.6 \mathrm{~km}$ resolution. (e) Difference between statistically downscaled (c) and modelled (d) runoff. (f) Difference between statistically downscaled (c) and bilinear interpolated (b) runoff.
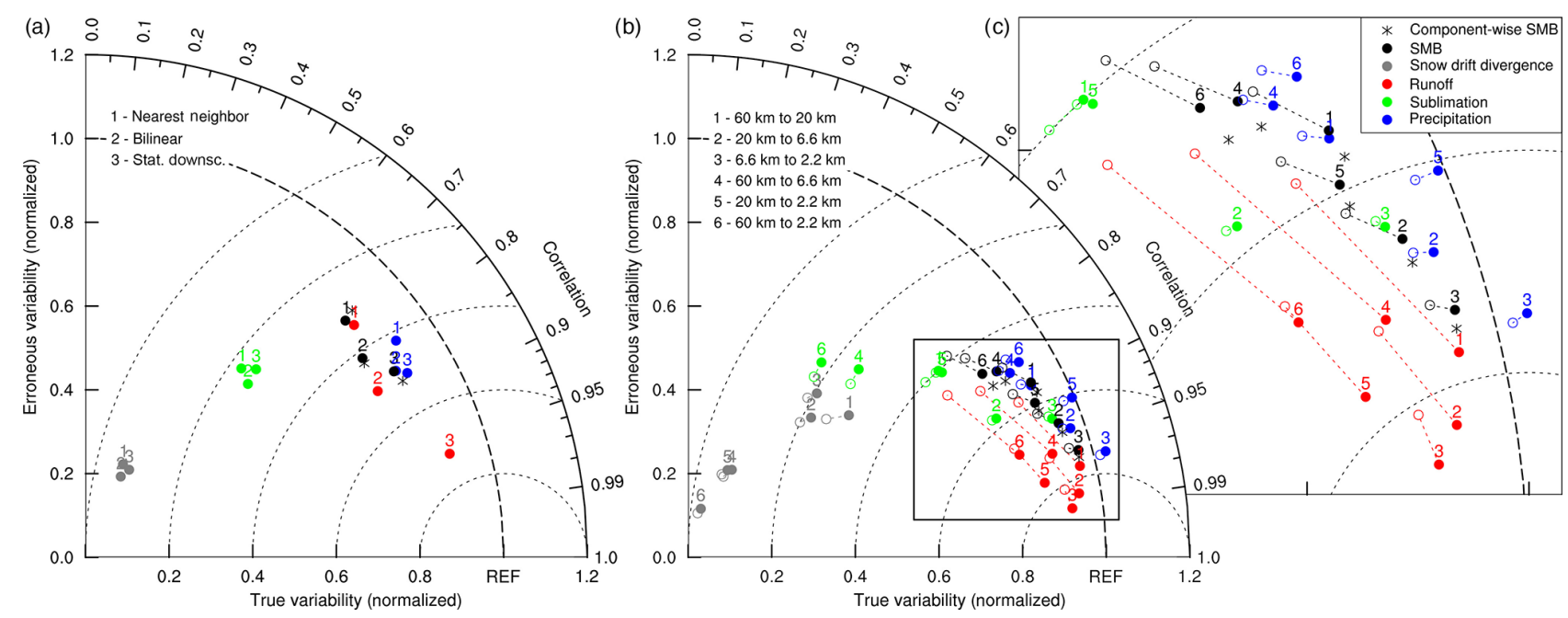

Figure 5. Taylor diagrams of the represented model variability for SMB and its components for (a) various refining procedures from 60 to $6.6 \mathrm{~km}$ and (b) bilinear (open circles) and statistical downscaling (filled circles) across all different model simulations, respectively, connected by dotted lines. (c) Zoom of the boxed point cluster in (b). The legend in (c) applies to all panels. The horizontal location in the Taylor graph gives the fraction of the true variability reproduced by the model; the vertical location is the amount of erroneous variability as fraction of the standard deviation of the reference dataset. 
only a minor contribution to SMB, this has little impact on the ability to refine SMB.

Finally, the representation of high-resolution SMB estimates from low-resolution SMB estimates improves through application of statistical downscaling (Fig. 5a). Componentwise statistical downscaling of SMB (black star adjacent to black dot no. 3) provides slightly better estimates of the SMB than statistical downscaling of the SMB itself (black dot no. 3). The differences are not large and enter through the constraints that are introduced in the refining step of individual components. For example, precipitation and runoff are both strictly positive, and precipitation is also modelled outside the ice sheet while runoff estimates are only derived on the ice sheet. The improvement of using component-wise statistical downscaling is likely larger if downscaling is applied to daily fields, when the local variations in precipitation and runoff are much more outspoken.

Figure $5 \mathrm{~b}$ and Table 3 provide the results of refining all six possible resolution combinations. In Fig. 5b, results of bilinear interpolation and statistical downscaling are shown with open and filled circles, respectively. In the case of snow drift divergence (grey markers) statistical downscaling does not provide distinctly better results than bilinear interpolation. Moreover, the $6.6 \mathrm{~km}$ resolution data are as different to $2.2 \mathrm{~km}$ data as the $60 \mathrm{~km}$ resolution data is different to the $20 \mathrm{~km}$ resolution data, as points 1 to 3 cluster together. Hence there is no convergence in the spatial patterns modelled by RACMO2. Snow drift divergence is largely driven by topography, with erosion at and upwind of crests and deposition downwind of these crests (Fig. S2). Hence, a consistent relation with topography is absent and the magnitude of erosion and deposition patterns increases with finer resolution as the topographic features become rougher. Nonetheless, erosion and deposition patterns over the interior ice sheet are almost equal in the 6.6 and $2.2 \mathrm{~km}$ resolution runs. The poor performance of statistical downscaling is due to the very different patterns modelled along the mountainous ice sheet margins in the southeast (Fig. S2c, d, and g) . Statistical downscaling also hardly brings low-resolution sublimation estimates (Fig. 5b, green markers) closer to high-resolution sublimation estimates compared to bilinear interpolation. However, the spatial pattern modelled at $6.6 \mathrm{~km}$ correlates well with the spatial patterns at $2.2 \mathrm{~km}$ (dot no. 3), so for sublimation a convergence to a definite spatial distribution starts to emerge, even though the $2.2 \mathrm{~km}$ has consistently less sublimation over the interior of the ice sheet and higher sublimation near the ice sheet margins (Fig. S1c, d, and g). A similar convergence is found for precipitation and for downscaled and bilinearly interpolated runoff and SMB (Fig. 5b). In all these cases, refined fields from 6.6 to $2.2 \mathrm{~km}$ (dot no. 3) are better than refined fields from 60 to $20 \mathrm{~km}$ (dot no. 1) with respect to resolved variability and remaining deviations (Table 3 ).

\subsection{Evaluation against observations}

In the preceding section, it is shown how and when statistical downscaling is expected to improve model results. In this section, we assess if statistical downscaling indeed increases the agreement with observations. For this aim, model data are interpolated or downscaled to the specific location of each observation.

First, model results are assessed using the "annual ablation" data, i.e. (sub-)annual, exactly time-matched ablation (Sect. 2.4). Table 4 shows that statistical downscaling, and especially component-wise statistical downscaling, strongly improves low-resolution results. In more detail, the correlation of bilinearly interpolated SMB estimates from 60 and $20 \mathrm{~km}$ resolution runs is low and the regression slope is largely underestimated. As ablation is occurring along the GrIS edges, model data are basically extrapolated to this edge to obtain a model estimate when refining low-resolution model data. As a result, the apparent observation elevations - which are interpolated in an equal manner as SMB - are strongly overestimated (Fig. 6a), leading to a considerable underestimation of the ablation rates (Fig. 6b). This error, due to a too coarse model topography, is already largely removed in the $6.6 \mathrm{~km}$ resolution results, and application of statistical downscaling does not further improve the estimated SMBs. Noteworthy is that the modelled SMB from the $2.2 \mathrm{~km}$ run clearly provides superior ablation estimates. This will be analysed in more detail in Sect. 3.4.

In Fig. 7a and c, the results presented in Table 4 are graphically represented. Since a normal Taylor diagram (e.g. Fig. 7a) does not display systematic biases, Fig. 7c has been added to include the contribution of the bias (horizontal axis) and the misrepresented variability (vertical axis) to the RMSD. In Fig. 7a, the amount of misrepresented variability is the deviation of model results from the reference data (REF) and shown in the dotted circles around this "REF" point. Although RACMO2 overestimates the SMB (Fig. 6), the bias is still a smaller contribution to the RMSD than the misrepresented variability. Furthermore, the reduction in the bias owing to the increase in model resolution or the application of statistical downscaling is larger than the decrease in the amount of missed variability (Fig. 7c). In both cases, high ablation locations are better resolved, which decreases the mean SMB and increases the variability. As the bias is relatively small for the best model results, the remaining source of error is the misrepresented variability in regional ablation. The contribution of misrepresented temporal variability is very small because the correlations and RMSDs of modelled SMB with the "period ablation" data, i.e. time-aggregated annual ablation data, are very similar to the values shown in Table 4 for the annual ablation data (not shown).

When all available ablation observations are used, the resulting performance changes slightly (circles in Fig. $7 \mathrm{~b}$ and d). This difference arises from the improved spatial coverage of the ablation zones of south Greenland. Again, increas- 
Table 4. Correlation, orthogonal regression slope, bias, and RMSD for bilinear (bl), statistically downscaled (sd), and component-wise statistically downscaled (csd) SMB to the location of the observation, respectively.

\begin{tabular}{lrrrr}
\hline Resolution & $\begin{array}{r}r \\
\mathrm{bl} / \mathrm{sd} / \mathrm{csd}\end{array}$ & $\begin{array}{r}\text { Regression slope } \\
\mathrm{bl} / \mathrm{sd} / \mathrm{csd}\end{array}$ & $\begin{array}{r}\text { Bias } \\
\mathrm{bl} / \mathrm{sd} / \mathrm{csd} \\
\mathrm{mw} . \mathrm{e} \cdot \mathrm{a}^{-1}\end{array}$ & $\begin{array}{r}\text { RMSD } \\
\mathrm{bl} / \mathrm{sd} / \mathrm{csd} \\
\mathrm{mw} . \mathrm{e} . \mathrm{a}^{-1}\end{array}$ \\
\hline $60 \mathrm{~km}$ & $0.19 / 0.43 / 0.57$ & $0.21 / 0.50 / 0.46$ & $1.31 / 1.01 / 0.80$ & $2.30 / 1.94 / 1.65$ \\
$20 \mathrm{~km}$ & $0.40 / 0.55 / 0.62$ & $0.49 / 0.55 / 0.57$ & $1.07 / 0.97 / 0.93$ & $2.02 / 1.78 / 1.66$ \\
$6.6 \mathrm{~km}$ & $0.63 / 0.62 / 0.62$ & $0.61 / 0.66 / 0.65$ & $0.67 / 0.67 / 0.68$ & $1.53 / 1.55 / 1.56$ \\
$2.2 \mathrm{~km}$ & $0.79 / 0.81 / 0.80$ & $0.76 / 0.77 / 0.76$ & $0.19 / 0.20 / 0.20$ & $1.10 / 1.05 / 1.07$ \\
\hline
\end{tabular}
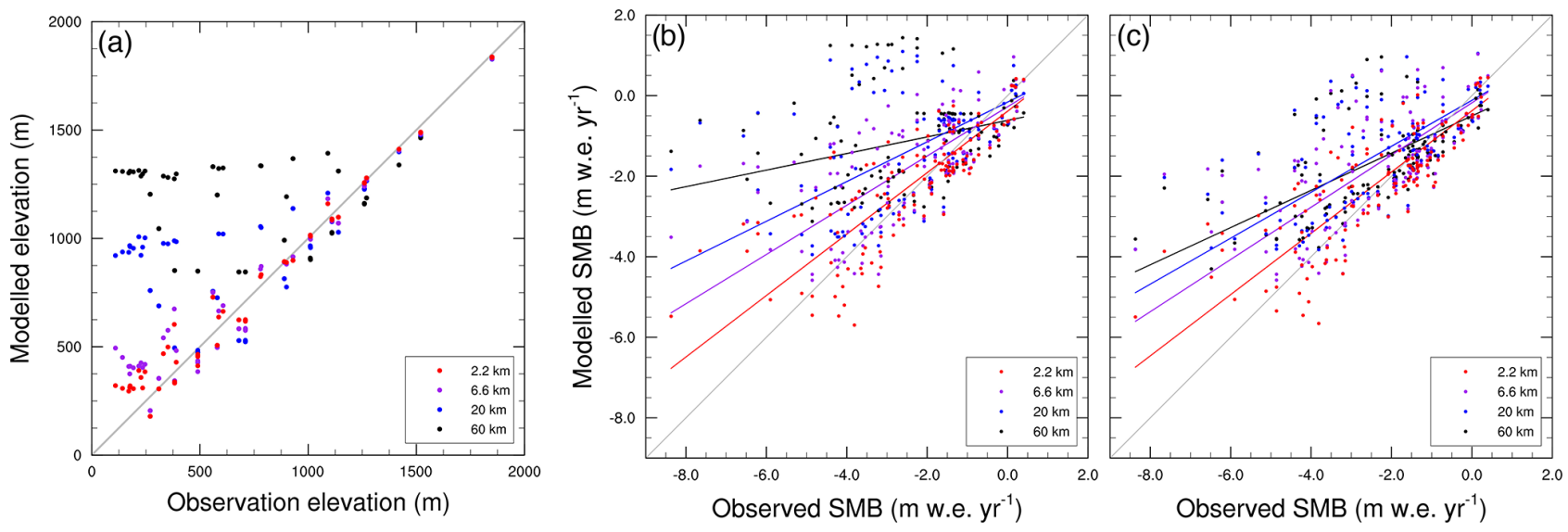

Figure 6. Estimated versus (a) true observational site elevation and (b, c) observed SMB for all four model resolutions using (a, b) bilinear interpolation and (c) component-wise statistical downscaling. Fits are derived using orthogonal regressions and the 1-to-1 line is drawn in grey for reference.

ing the resolution as well as applying statistical downscaling both improve the results. Note that for 60 and $20 \mathrm{~km}$ model data component-wise statistical downscaling provides the best results, while for 6.6 and $2.2 \mathrm{~km}$ model data statistical downscaling of the modelled SMB gives slightly better results. Since component-wise statistical downscaling of SMB should theoretically outperform statistical downscaling of the SMB itself, this outcome may indicate that for the modelled SMB at 6.6 and $2.2 \mathrm{~km}$ resolution model shortcomings become more important than lack of resolution. Furthermore, although the $2.2 \mathrm{~km}$ simulation provides the results with the lowest RMSD, ablation is now overestimated as the bias has become negative (Fig. 7d). This overestimation could be due to the enhanced ablation in the most recent decades. The "average ablation" dataset includes many observations made between 1950 and 1980 when ablation was known to be less than in recent decades. In order to quantify the potential impact of this recent decrease in SMB on the bias, the average ablation dataset is also compared with modelled SMB of the RACMO2.3p2 simulation at $5.5 \mathrm{~km}$ (Noël et al., 2019) using both the full simulation length (1958-2018) and the specific time frame used here (2007-2014), showing that this temporal shift in SMB could be the same order of magnitude as the SMB biases of the statistically downscaled SMB estimates.
The behaviour of model performance as a function of resolution and refinement technique is very different in the accumulation zone (Fig. $7 \mathrm{~b}$ and d, stars). The $60 \mathrm{~km}$ resolution is insufficient to estimate accumulation as the variability is overestimated (1.25 to 1.4 times observed variability, Fig. 7b) due to erroneous variability that is of the same magnitude as the observed variability. However, little to no gain in performance is seen between the 20,6.6, and $2.2 \mathrm{~km}$ model results, and statistical downscaling has no added value, as the stars belonging to these resolutions are clustered in both panels. Of course, the possible impact of statistical downscaling was reduced by excluding observations with strongly deviating elevations. Furthermore, bilinear estimates are in most cases slightly better than statistically downscaled estimates. This result is in line with the earlier conclusion that statistical downscaling is not a suitable method for refining precipitation fields. We conclude that the quality of the modelled accumulation depends on the ability of the RCM or general circulation model (GCM) to model precipitation patterns and that a resolution of about $20 \mathrm{~km}$ is enough to resolve the spatial patterns over the majority of the GrIS in south Greenland. Please note that in absence of observations, the modelled accumulation along the rugged southeastern margin of the GrIS cannot be evaluated. 


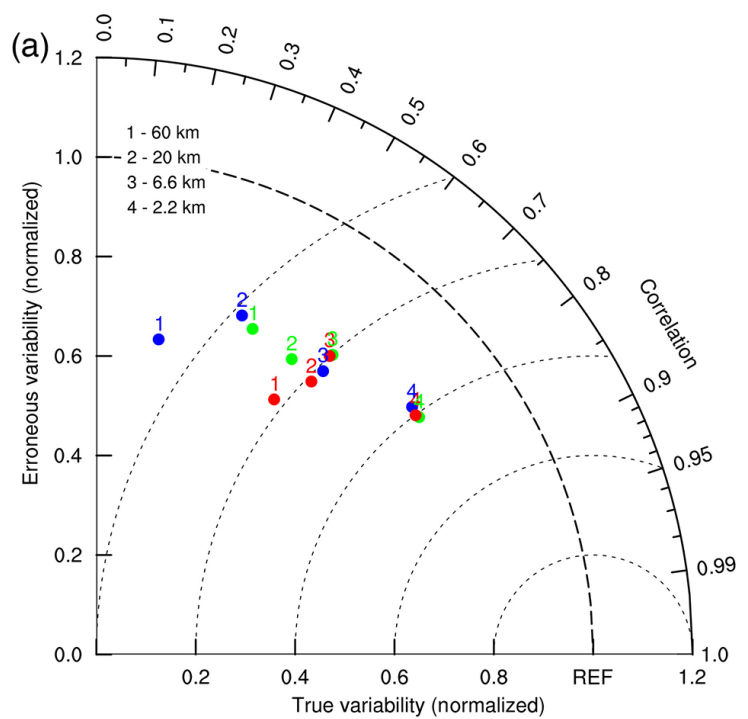

(c)

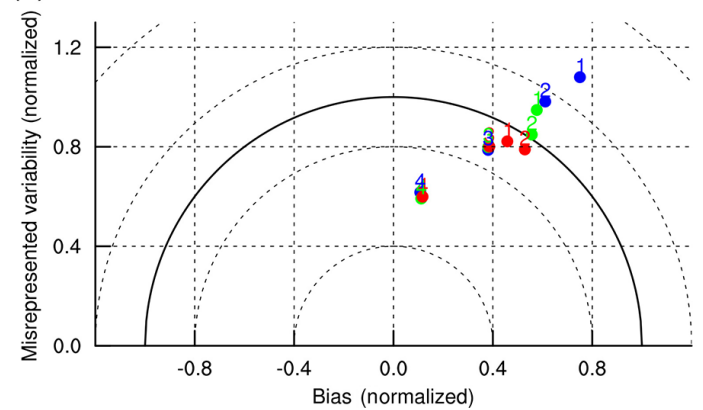

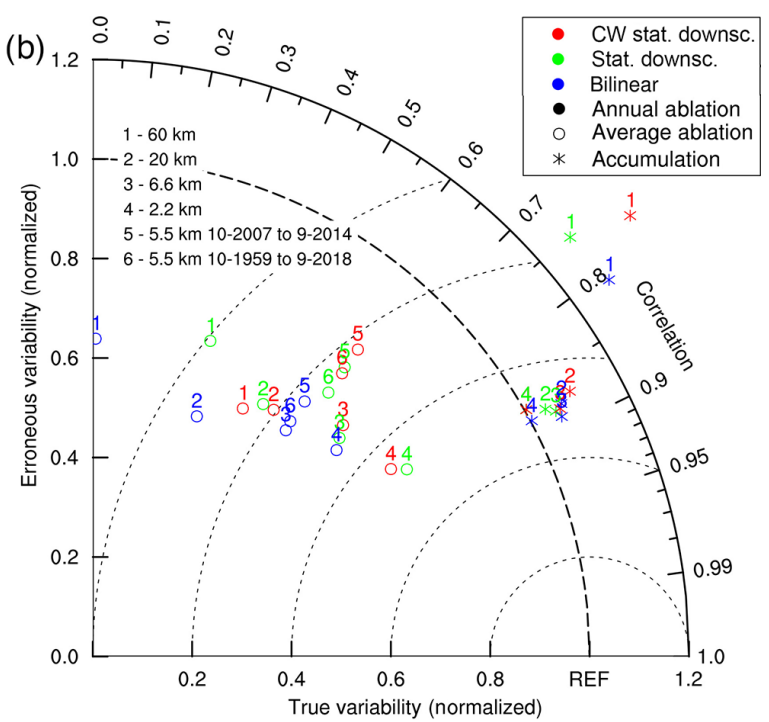

(d)

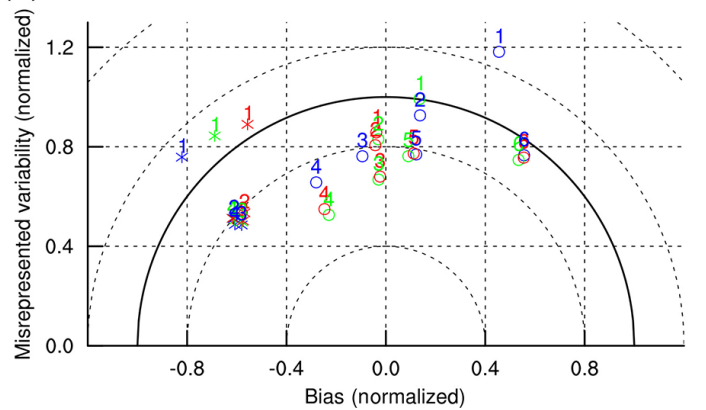

Figure 7. Graphical representation of the statistics of refined RACMO2 data for (a, c) exact time-matching ablation observations and (b, d) all ablation (circles) and accumulation (stars) observations. Panels (a, b) are Taylor diagrams; panels (c, d) show the contribution of the bias (horizontal axis) and misrepresented variability (vertical axis) to the RMSD (circles around $(0,0)$ ). All data in this figure are scaled with the standard deviation of the observation dataset. The $5.5 \mathrm{~km}$ data are taken from Noël et al. (2019). The legend in (b), upper right corner, applies to all panels.

\subsection{Analysis of the $2.2 \mathrm{~km}$ run}

There are three linked causes for the improved performance of the modelled SMB at $2.2 \mathrm{~km}$ resolution. They are discussed by comparing model results obtained at $2.2 \mathrm{~km}$ and $6.6 \mathrm{~km}$ resolution.

Firstly, less precipitation is modelled at $2.2 \mathrm{~km}$ than at $6.6 \mathrm{~km}$ resolution for most of the margin of the GrIS (Fig. 8a). Over the GrIS, these reductions are most outspoken west of Tasiilaq and north of Narsaq, where, by chance, many of the ablation observations were also located. In general, precipitation is reduced in the $2.2 \mathrm{~km}$ simulation compared to the $6.6 \mathrm{~km}$ simulation in coastal regions with relatively less rugged terrain. More precipitation is modelled over heavily rugged terrain and over sea at some distance from the coast. The differences are generally very small over the interior ice sheet; hence the performance representing the accumulation observations is similar.

The second and third causes are related to runoff as more runoff is modelled for the lower ablation zones (Fig. 8b).
This is partly due to the lower precipitation as less precipitation reduces the meltwater buffering capacity of the firn layer for refreezing in spring. Subsequently, less precipitation leads to earlier surfacing of dark glacial ice during the ablation season. This results in similar patterns for precipitation and runoff. Runoff is further enhanced in the $2.2 \mathrm{~km}$ run by a higher sensible heat flux (SHF) towards the surface in the outer $20 \mathrm{~km}$ of the ice sheet (Fig. 8c). More detailed analysis (not shown) reveals that SHF is also increased during melt events, thus indeed enhancing melt, and that both higher atmospheric temperatures and higher wind speeds contribute to the increase in SHF during melt events. Observations from automated weather stations (AWSs) point out that heat advection onto the ice sheet is a major driver of melt in the lower ablation zone, and the contribution of the SHF to melt is often underestimated in (regional) climate models (Fausto et al., 2016). However, it cannot be proven that the higher SHF is more realistic. An equivalent analysis of the $6.6 \mathrm{~km}$ results with respect to the $20 \mathrm{~km}$ results (Fig. S3c) reveals 

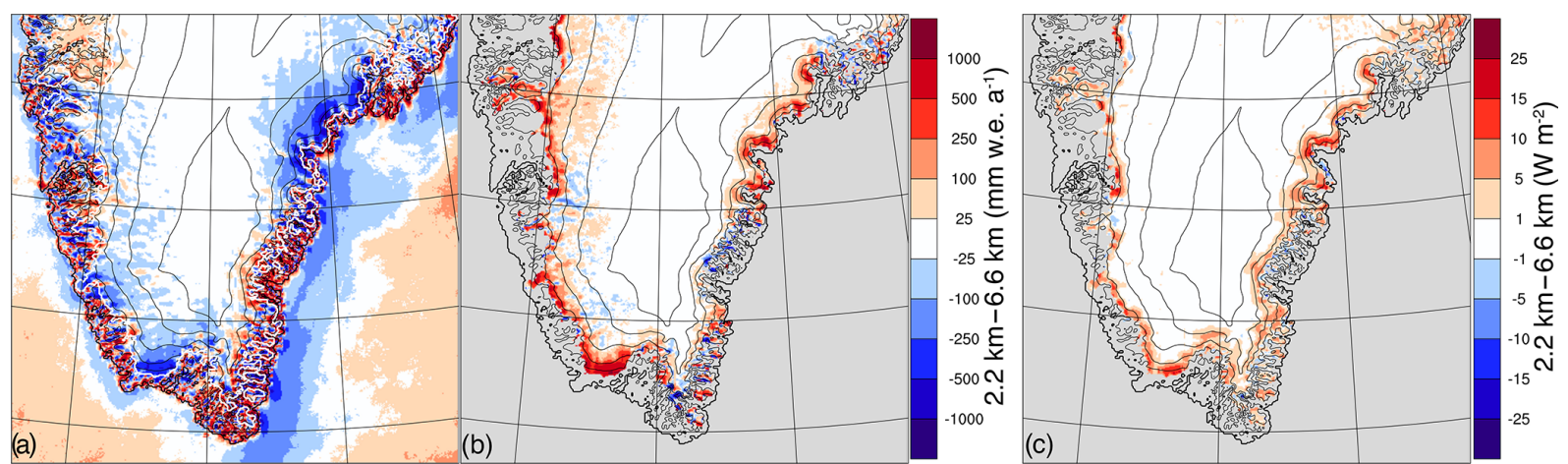

Figure 8. Differences in the mean (a) precipitation, (b) runoff, and (c) sensible heat flux between the 2.2 and $6.6 \mathrm{~km}$ simulations. The sensible heat flux is positive if pointed towards the surface. The $6.6 \mathrm{~km}$ results are mapped on the $2.2 \mathrm{~km}$ grid using bilinear (a) and statistical downscaling (b, c), respectively.

a similar increase in SHF, however with spread over a 3fold wider zone and a lower magnitude to at most $10 \mathrm{~W} \mathrm{~m}^{-2}$. Since all model runs were performed with the same settings and similar time step lengths, the most probable reason for the increase in SHF is that a finer resolution allows for more dynamic heat advection onto the ice sheet at length scales up to 10 times the grid resolution.

Such systematic differences in runoff and precipitation are absent when comparing the $6.6 \mathrm{~km}$ run with lower-resolution runs (Fig. S3). Of course, topography-induced periodic patterns arise in the $6.6 \mathrm{~km}$ run (e.g. Fig. 3d), but no regional decreases or increases of precipitation and runoff are found. These patterns were also not expected given the similar error margins compared to observations (e.g. Fig. 7a).

Figure S4 displays the differences between the modelled large-scale and convective precipitation at $2.2,6.6$, and $20 \mathrm{~km}$ resolution. Over the GrIS, more than $90 \%$ of the precipitation is large-scale precipitation, and the precipitation differences over the GrIS (Fig. 8a) are predominantly due to changes in modelled large-scale precipitation (Fig. 4c). A plausible explanation for the changes in large-scale precipitation over land is that the regional precipitation patterns are caused by the flow patterns which arise by operating a hydrostatic model over rugged terrain while using resolutions as fine as $2.2 \mathrm{~km}$. In the $2.2 \mathrm{~km}$ run, standing "supercritical flow"-like waves throughout the atmosphere are modelled fairly regularly over the mountainous coastal areas of south Greenland. These patterns are stronger over the more rugged coastal mountains (southeastern coast) and tundra zone (southwestern coast) than over the ice sheet as ice sheets strongly dampen topographic gradients due to the diffusive nature of ice flow. The momentum of the related vertical motion up to $10 \mathrm{~m} \mathrm{~s}^{-1}$ is not conserved due to the applied hydrostatic assumption in RACMO2, which may lead to overestimated upward and downward motion. These waves induce (wet-)adiabatic cooling of air and subsequently extract humidity efficiently from the atmosphere through precipitation formation, which in turn leads to a reduction of available wa- ter vapour downstream and, therefore, to lower precipitation rates where topography favouring the generation of atmospheric waves is absent. These waves may or may not be realistic, but they will be better dealt with in a non-hydrostatic model.

Over sea, changes are due to different processes. Figure $\mathrm{S} 4 \mathrm{c}$ shows that large-scale precipitation is rather uniformly reduced over the whole Atlantic sector in the model domain in the $2.2 \mathrm{~km}$ simulation. Similar reductions, however now for all ocean grid points, are visible between the 6.6 and $20 \mathrm{~km}$ simulations (Fig. S4e) and, to a lesser extent, between the 20 and $60 \mathrm{~km}$ simulations (not shown). No clear explanation nor reason has been found for this decrease. Away from the coast, convective precipitation is enhanced in the $2.2 \mathrm{~km}$ simulation compared to the $6.6 \mathrm{~km}$ simulation (Fig. S4d). This enhanced convection is likely surface temperature driven, as this convective precipitation is not observed along the Greenland coast where sea surface temperatures are lower due to the East Greenland Current and seasonal sea ice. Given the importance of convective precipitation over the Atlantic Ocean, the validity of the model results is seriously affected by the choice to keep the parameterisation of convection equal for all model resolutions. Even though convection in these cold, shallow tropospheric atmospheric conditions may remain on kilometre scales, thus at a similar scale as the $2.2 \mathrm{~km}$ model grid resolution, it is disputable at least whether the used approach for convection is right.

Concluding, RACMO2 run at $2.2 \mathrm{~km}$ resolution provides superior results for the lower ablation zone due to changing precipitation patterns. Yet, these results may in part be caused by the limitations set by the hydrostatic assumption in RACMO2 and questionable choices for convection. Nonetheless, it also shows that at coarser resolutions precipitation is a source of error. Finally, the absence of similar precipitation patterns in the $6.6 \mathrm{~km}$ run and in the RACMO2.3p2 $5.5 \mathrm{~km}$ run compared to the RACMO2.3p2 $11 \mathrm{~km}$ run (Noël et al., 2018; Noël et al., 2019, not shown) indicates that 
RACMO2 can be applied at resolutions down to about $5 \mathrm{~km}$. Concluding, non-hydrostatic models can not be used in polar regions at resolutions below $5 \mathrm{~km}$, even if convection is suitably represented.

\subsection{Sensitivity of model performance to parameterisation choices}

In the preceding sections the impact of resolution and of data refinement on the model performance has been discussed. For a perfect model, insufficient resolution would be the only source of errors. RACMO2 is, as any other model, not perfect, so for a certain resolution the intrinsic model errors would become of larger importance than the errors induced by the limited model resolution. In order to estimate intrinsic error due to parameterisation and model initialisation choices in comparison to the changes in differences induced by model resolution, eight additional full-period runs on the $20 \mathrm{~km}$ domain have been carried out targeting four known possible sources of error: firn initialisation, snow densification, albedo, and turbulent exchange of heat and moisture. Similar to the reference simulations, the analysis below, the first year of all simulations is excluded.

\subsubsection{Firn initialisation}

The reference runs at various resolutions were initialised with a spatially uniform fresh snow cover of $50 \mathrm{~cm}$, leading to limited refreezing capacity in the accumulation zone. Figure 9a (run 1) shows the increase in SMB if the run was started with a spatially uniform layer of $10 \mathrm{~m}$ firn. A gradually increasing impact is visible from a small increase in SMB in the higher percolation zone up to $500 \mathrm{mmw}$.e. $\mathrm{a}^{-1}$ higher SMB in the lower ablation zone. This spin-up effect lasts only for a few years, because if the first 4 years are discarded, hence more vigorously excluding firn spin-up effects, the SMB in the lower ablation zone (SMB $\ll-2$ mw.e. $\mathrm{a}^{-1}$ ) is comparable with the reference run (not shown). In the higher ablation and the percolation zones the SMB is still increased by up to $400 \mathrm{~mm}$ w.e. $\mathrm{a}^{-1}$. The effect of initialising with an incorrect firn layer lasts longest close to the equilibrium line, which is also the region where the refreezing also has an impact on the SMB.

These changes are not observed if the run is initialised with $3 \mathrm{~m}$ of firn (run 2, not shown); for this run the differences to the reference run are limited to about $20 \mathrm{~mm}$ w.e. $\mathrm{a}^{-1}$. Hence, $3 \mathrm{~m}$ firn initialisation does not affect melt in the ablation zone for periods beyond 2 years, which is a positive effect; however, it also does not provide the required refreezing capacity in the percolation zone, which is a negative effect. These runs show that in order to obtain accurate estimates of the SMB in both the percolation zone and the ablation zone, a proper initialisation of the firn and ice state is essential.

\subsubsection{Firn compaction parameterisation}

Next, a run is carried out using the densification parameterisation of Ligtenberg et al. (2011), fed with accumulation rates from the reference run. Using Ligtenberg et al. (2011) yields an increase in melt of 10 to $50 \mathrm{~mm}$ w.e. $\mathrm{a}^{-1}$ in the western ablation zone (run 3 , not shown). This difference is due to the lower density of the winter snow, which reduces the ground heat flux in spring, allowing a slightly earlier onset of and subsequently stronger snowmelt. Along the eastern coast, runoff is enhanced up to $150 \mathrm{~mm}$ w.e. $\mathrm{a}^{-1}$. This enhancement is partly due to lower snow densities of near-surface snow and to faster compaction of the highaccumulation firn layer, leading to a reduction in pore space for water retention and, therefore, to higher runoff rates and lower SMB. Densification has thus a small but measurable impact on the SMB.

\subsubsection{Albedo}

Two runs were carried out to assess the impact of albedo on the SMB. In the first run (run 4), a uniform bare-ice albedo of 0.38 is used, which is 0.04 lower than the value used in the reference simulations. A bare-ice albedo of 0.38 is rather low, but such values are observed in several regions of the ablation zone, especially where dust and algae accumulate (Noël et al., 2018). As expected, a lower ice albedo enhances melt and thus lowers the SMB up to $300 \mathrm{mmw}^{-e . \mathrm{a}^{-1}}$ (Fig. 9b). Note that the lower ablation zone, where the bare-ice albedo influences SMB most, is underrepresented at this resolution, so the sensitivity of SMB to ice albedo is probably higher at finer resolutions. This experiment reaffirms that it is important to have an accurate estimate of the ice albedo.

In the second run (run 5), the soot content in snow is reduced from 0.10 to $0.05 \mathrm{ppmv}$, which has a similar but opposite effect on SMB (Fig. 9c) as the change in bare-ice albedo. Less soot primarily increases snow albedo in winter and spring, which delays the onset of melt and snow metamorphism, reducing the melt and runoff in the percolation zone. In the ablation zone, lowering the soot concentration reduces runoff even more efficiently because when the onset of melt is delayed the moment of bare-ice surfacing is delayed as well. Hence, runoff is most sensitive to the soot content in snow in regions with both high melt and high precipitation rates.

\subsubsection{Turbulent exchange}

Three runs were performed to examine the sensitivity of the SMB to the parameterisations of turbulent fluxes. Currently, RACMO2 uses a roughness length for momentum $\left(z_{0 \mathrm{~m}}\right)$ of $1 \mathrm{~mm}$ over snow and $5 \mathrm{~mm}$ over bare ice and the roughness lengths for heat $\left(z_{0 \mathrm{~h}}\right)$ and moisture $\left(z_{0 \mathrm{q}}\right)$ are determined using Andreas (1987) over snow and Smeets and van den Broeke (2008b) over bare ice. In run $6, z_{0 \mathrm{~m}}$ over bare ice 


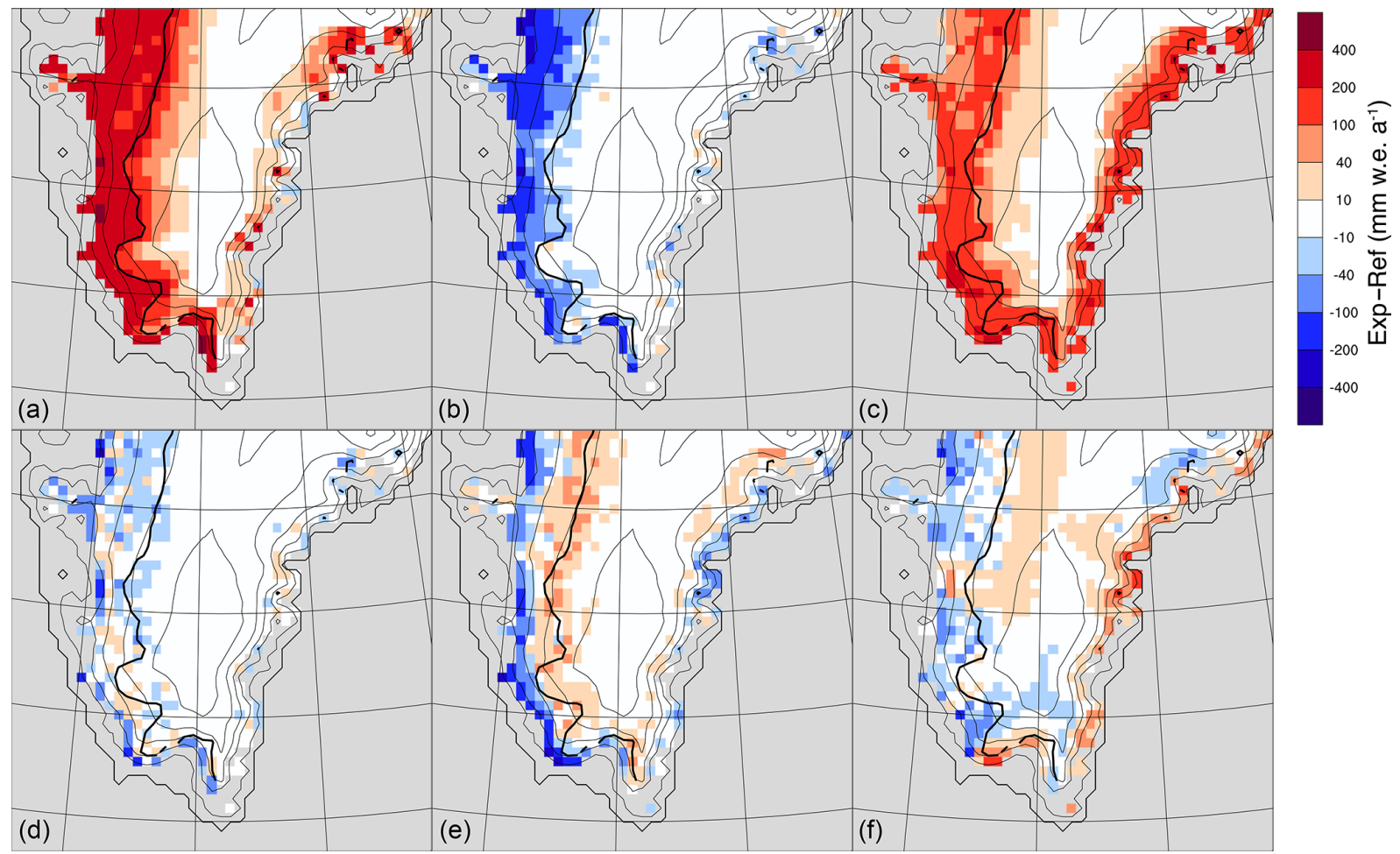

Figure 9. Difference in modelled SMB compared to the reference run from six of eight sensitivity test runs at $20 \mathrm{~km}$ resolution; October 2007 to September 2014 average: (a, run 1) uniform $10 \mathrm{~m}$ firn layer, (b, run 4) a reduced bare-ice albedo by 0.04 to 0.38 , (c, run 5) the soot concentration in the snow halved to $0.05 \mathrm{ppmv},(\mathbf{d}$, run 6$)$ the roughness length of momentum of bare ice increased to $10 \mathrm{~cm}$, and (e, run 7 ; f, run 8) equal roughness lengths of momentum, heat, and moisture, with $1 \mathrm{~cm}$ over ice and (run 7) $1 \mathrm{~mm}$ or (run 8) $0.1 \mathrm{~mm}$ over snow. In all figures the equilibrium line in the reference run is drawn with a thick line for reference.

is increased to $10 \mathrm{~cm}$, which represents a very rough terrain (Smeets and van den Broeke, 2008a). Although this is a 20fold increase in $z_{0 \mathrm{~m}}$, the effect on the modelled melt and thus on the SMB is limited (Fig. 9d). In the parameterisations of Andreas (1987) and Smeets and van den Broeke (2008b), $z_{0 \mathrm{~h}}$ and $z_{0 \mathrm{q}}$ are decreasing functions of the roughness Reynolds number $\left(R_{\star} \equiv u_{\star} z_{0} / v\right.$, with $u_{\star}$ and $v$ being the friction velocity and kinematic viscosity of air, respectively). Increasing $z_{0 \mathrm{~m}}$ increases the aerodynamic drag but also $R_{\star}$, which strongly reduces the increase in turbulent heat and moisture exchange for higher $z_{0 \mathrm{~m}}$.

It should be noted that Andreas (1987) uses the assumption of a neutral boundary layer for his derivation of $z_{0 \mathrm{~h}}$ and $z_{0 \mathrm{q}}$ and the subsequent heat and moisture fluxes over snow. The variations in $z_{0 \mathrm{~h}}$ and $z_{0 \mathrm{q}}$ are thus not only a surface property but include flow properties as well, namely the limiting effect of the stable boundary layer on the turbulent fluxes. Smeets and van den Broeke (2008b) correct for the limiting effect of the stable boundary layer on the turbulent exchange, but they use relatively simple corrections (Pandolfo, 1966). Hence, $z_{0 \mathrm{~h}}$ and $z_{0 \mathrm{q}}$ are still partly stable boundary flow properties and not solely surface properties. In RACMO2, however, the limiting effect of the stable boundary layer on the turbulent fluxes is already incorporated by using a modi- fied version of the advanced gradient functions proposed by Holtslag and de Bruin (1988). Hence, using both turbulencedependent values for $z_{0 \mathrm{~h}}$ and $z_{0 \mathrm{q}}$ and complex stability functions could lead to overcompensating for the limiting effect of a stable boundary layer on the turbulent fluxes.

Therefore, two experiments were performed in which $z_{0 \mathrm{~h}}$ and $z_{0 \mathrm{q}}$ were kept equal to $z_{0 \mathrm{~m}}$. In run 7 (Fig. 9e) $z_{0 \mathrm{~m}}$ was set to 1 and $10 \mathrm{~mm}$ over snow and ice, respectively. In this run the turbulent exchange is more efficient; the difference with the reference run is most prominent in the lower ablation zone where warm air reaches over the ice sheet. The enhancement of runoff in the ablation zone is larger than in the preceding sensitivity run (Fig. 9d) in which $z_{0 \mathrm{~m}}$ over ice was increased to extreme values. Near the equilibrium line, the run shows that enhanced turbulent exchange generally results in reducing the melt and hence increasing the SMB. Finally, as we did not aim to enhance exchange over snow, a run was executed in which $z_{0 \mathrm{~m}}$ was set to 0.1 and $10 \mathrm{~mm}$ over snow and ice, respectively (run 8, Fig. 9f). In run 8 , the turbulent exchange decreases slightly over snow, generally leading to more melt, compared to run 7, in the percolation zone. Along the margins of the ice sheet, snowmelt is reduced and subsequently the SMB increases as the turbulent fluxes contribute less to removing the spring snow cover. 


\subsubsection{Sensitivity test run evaluation}

Figure 10 shows whether the set of test runs improve or deteriorate the comparison with observations. In many cases the differences with the reference run in predicting performance are very small, as the differences in modelled SMB are not large either. Including a firn layer, decreasing the soot content, or fixing the roughness lengths (runs 1, 5, and 7) decrease runoff in the percolation zone, reducing the bias and amount of misrepresented variability in the accumulation zone (Fig. 1, red dots). However, the subsequent reduction of melt in the ablation zone in runs 1 and 5 decreases the performance in representing ablation (Fig. 1, magenta, blue, and green dots). All other test runs have little impact on the accumulation zone and subsequently exhibit similar performance in representing the accumulation observations. Lowering the bare-ice albedo (run 4) does change the bias in the ablation zone; however, the correlation of the model results with the observations does not increase. This test run shows, thus, that it is imperative to have an accurate spatial and temporal description of ice albedo as moderate changes (e.g. 0.04) already have a significant effect on the local SMB. The only change that generally improves the results is using constant $z_{0 \mathrm{~h}}$ and $z_{0 \mathrm{q}}$ (run 7). This test run increases the gradient in the ablation zone, which is underestimated in all other test runs (Fig. 6c).

\section{Discussion}

This research aims, firstly, to find the optimal resolution at which global or regional atmospheric models must be run in order to produce realistic SMB estimates; secondly, to which extent statistical downscaling can replace full model simulations; and, thirdly, which physical processes represent the largest sources of error in final SMB estimates.

Simulations performed at various resolutions indicate that high-resolution dynamical downscaling, i.e. running an $\mathrm{RCM}$, in combination with further refining through application of statistical downscaling, in principle provides the best estimate of the SMB in both the accumulation zone of the southern GrIS and the ablation zone. Nevertheless, the results show that the performance gain by increasing the resolution flattens out. A resolution of $20 \mathrm{~km}$ is sufficient to resolve the accumulation zone of the GrIS; $6.6 \mathrm{~km}$ resolution is sufficient to resolve most of the ablation zone, and at $2.2 \mathrm{~km}$ almost all details of the GrIS and the larger peripheral glaciers are resolved. The regions of improvement represent a progressively smaller fraction of Greenland; however these regions near the margin exhibit, for example, the highest ablation rates. Nevertheless, the impact of the improvements induced by grid refinement on the overall SMB likely decreases as well (Lang et al., 2015; Fettweis et al., 2017). An exception could be the instance that the overall model behaviour changes due to increased model resolution. The runs
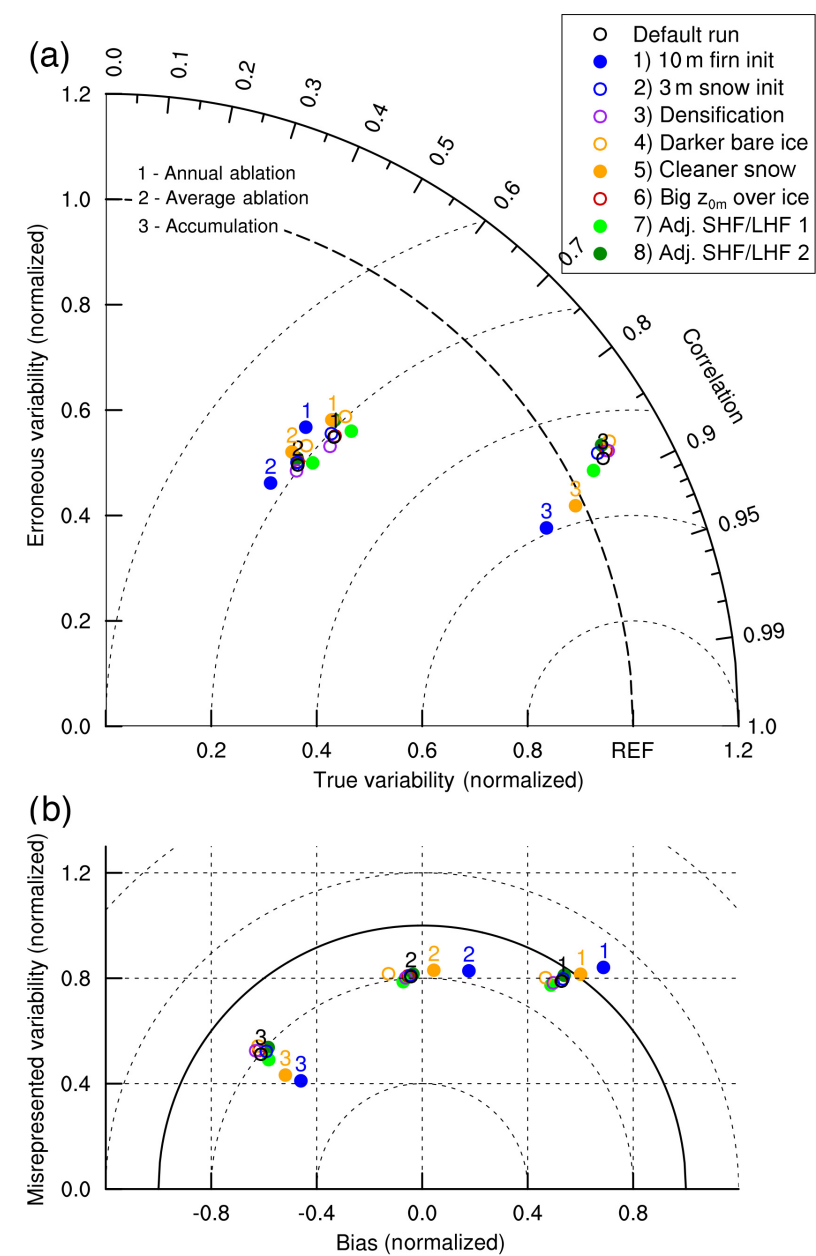

Figure 10. Sensitivity of the comparison of modelled SMB to observations as a function of snow initialisation, tuning, and specific parameterisations, all derived using the $20 \mathrm{~km}$ resolution domain expressed by (a) a Taylor diagram and (b) RMSD contribution diagram like Fig. $7 b$ and d.

at various resolutions and the accompanying methods of interpolation show that statistical downscaling only improves runoff estimates significantly; for all other SMB components the beneficial impact is marginal. As runoff is the dominating SMB component in the ablation zone, statistical downscaling does improve SMB estimates in such regions, especially if all components are refined separately. However, statistical downscaling cannot fully replace high-resolution dynamical downscaling simulations. Additionally, fractional glacier ice masks, which are not tested in this research, have shown to improve statistical downscaling as this approach also provides estimates of SMB components outside the glaciated domain.

The simulation at $2.2 \mathrm{~km}$ resolution also clearly shows that the hydrostatic assumption in RACMO2 sets a lower mesh limit of about $5 \mathrm{~km}$ below which model results are no longer physically correct. Ironically, the regional shifts in precipita- 
tion patterns induced by the vertical air motion over topography lead to the best estimates of SMB. It also shows that changes in the precipitation flux in the ablation zone count double as more snowfall increases the buffering capacity for refreezing and shortens the time that dark glacial ice is exposed at the surface.

Although we did not carry out further sensitivity tests with a direct focus on precipitation or clouds, processes involving these parameters can be significant sources of error in the modelled climate and subsequent SMB. Modelled precipitation patterns are harder to tune than ablation as local precipitation is the result of the interplay between the large-scale circulation and cloud microphysics. Noël et al. (2018) demonstrate that retuning the microphysics parameters in the cloud scheme of RACMO2 can change the ratio between the precipitation deposited inland and along the coast. In addition, the microphysics currently used in RACMO2 is effectively not treating cloud water and cloud ice as separate prognostic variables; subsequently, for example, it underestimates the occurrence of cloud water over the ice sheet (Van Tricht et al., 2016). Furthermore, RACMO2 has no horizontal advection of hydrometeors, which leads to too pronounced precipitation maxima on the windward side of topography (Lenaerts et al., 2017; Agosta et al., 2019).

The sensitivity tests show that for optimal estimates a proper firn initialisation and spatially variable - and ideally also time-varying - glacial ice albedos are essential; both are not used here. Remote sensing provides detailed estimates of the glacial ice albedo; however, there is not yet an established method to estimate the bare-ice albedo and its evolution. Such a parameterisation will be very beneficial for simulations of past and future climate. Proper firn initialisations can be made using dedicated firn densification models; a priori knowledge of the location of the equilibrium line can be included if an initialisation for the present-day climate is prepared. However, even if those efforts are made, refreezing is most uncertain in the vicinity of the equilibrium line, where the refreezing capacity directly influences the SMB: the time in which a firn column adjusts is longest and the meltwater percolation processes - ice lenses or aquifer formation - are very complex (Forster et al., 2013; Machguth et al., 2016a).

Compared to the impact of precipitation, firn initialisation, and albedo, the impact of the parameterisation of the turbulent fluxes on the SMB is relatively small. Nonetheless, further research on the parameterisation of the turbulent fluxes is required, as our tests show that melt rates at the margins can be quite sensitive to parameterisation choices. Neither the default surface roughness parameterisation in RACMO nor the alternatively tested versions are to yield the best estimates of the turbulent fluxes. In order to make progress in the formulation of turbulent exchange under conditions of strong turbulent-driven melt, dedicated flux measurements are required.

\section{Conclusions}

Concluding, the results show that with a dynamical model, i.e. an ESM, GCM, or RCM, run at a resolution of $20 \mathrm{~km}$ $\left(\sim 0.25^{\circ}\right)$ and subsequent statistical downscaling, reasonably good results for both the accumulation and ablation zones are obtained. An exception might be the rugged coastal accumulation zone of southeast Greenland where accumulation observations are missing. Yet, running a dynamical model at a higher resolution and subsequently applying statistical downscaling leads to better results. In the case of RACMO2, the best results are achieved with the $2.2 \mathrm{~km}$ simulation, a resolution, however, at which the hydrostatic assumption of RACMO2 is no longer valid. At this resolution local enhancement or reduction of precipitation formation due to topographically induced vertical motion is no longer negligible. Nonetheless, the modelled significant vertical motions at this resolution lead to better-matching spatial precipitation patterns. Additional sensitivity tests show that using higher resolution is only one aspect in further improving the estimated SMB. Of approximately similar importance are (a) a proper initialisation of the firn layer in the accumulation zone, (b) the representation of the spatial and temporal variation in the albedo of glacial ice, (c) correct estimates of the turbulent fluxes during melting events, and (d) the representation of the local and regional precipitation patterns. Only once all these aspects are properly resolved in a well balanced manner can the uncertainty and error in the modelled SMB of the GrIS be further reduced.

Data availability. The main datasets presented in this study can be downloaded from https://doi.org/10.5281/zenodo.3568129 (Van de Berg et al., 2019). Additional datasets are available from the authors upon request and without conditions.

Supplement. The supplement related to this article is available online at: https://doi.org/10.5194/tc-14-1809-2020-supplement.

Author contributions. WJvdB prepared the manuscript, conducted the RACMO2 simulations, and analysed the data. EvM and $\mathrm{LHvU}$ provided assistance in setting up the simulations. All authors commented on the manuscript.

Competing interests. The authors declare that they have no conflict of interest.

Acknowledgements. We acknowledge ECMWF for the use of their computing and archive facilities in this research. Horst Machguth is thanked for collecting and freely sharing his very relevant ablation observation dataset. 
Review statement. This paper was edited by Xavier Fettweis and reviewed by Masashi Niwano and two anonymous referees.

\section{References}

Agosta, C., Amory, C., Kittel, C., Orsi, A., Favier, V., Gallée, H., van den Broeke, M. R., Lenaerts, J. T. M., van Wessem, J. M., van de Berg, W. J., and Fettweis, X.: Estimation of the Antarctic surface mass balance using the regional climate model MAR (19792015) and identification of dominant processes, The Cryosphere, 13, 281-296, https://doi.org/10.5194/tc-13-281-2019, 2019.

Andreas, E. L.: A theory for the scalar roughness and the scalar transfer coefficients over snow and sea ice, Bound.-Lay. Meteorol., 38, 159-184, 1987.

Arthern, R. J., Vaughan, D. G., Rankin, A. M., Mulvaney, R., and Thomas, E. R.: In situ measurements of Antarctic snow compaction compared with predictions of models, J. Geophys. Res., 115, F03011, https://doi.org/10.1029/2009JF001306, 2010.

Bales, R. C., McConnell, J. R., Mosley-Thompson, E., and Csatho, B.: Accumulation over the Greenland ice sheet from historical and recent records, J. Geophys. Res., 106, 33813-33825, 2001.

Bales, R. C., Guo, Q., Shen, D., McConnell, J. R., Du, G., Burkhart, J. F., Spikes, V. B., Hanna, E., and Cappelen, J.: Annual accumulation for Greenland updated using ice core data developed during 2000-2006 and analysis of daily coastal meteorological data, J. Geophys. Res., 114, D06116, https://doi.org/10.1029/2008JD011208, 2009.

DuVivier, A. K. and Cassano, J. J.: Evaluation of WRF Model Resolution on Simulated Mesoscale Winds and Surface Fluxes near Greenland, Mon. Weather Rev., 141, 941-963, https://doi.org/10.1175/MWR-D-12-00091.1, 2013.

Dyer, A. J. and Hicks, B. B.: Flux-gradient relationships in the constant flux layer, Q. J. Roy. Meteor. Soc., 96, 715-721, 1970.

ECWMF-IFS: Part IV: Physical Processes (CY33R1), Tech. rep., European Centre For Medium-Range Weather Forecasts (ECMWF), available at: https://www.ecmwf.int/node/9227 (last access: 3 June 2020), 2009.

Ettema, J., van den Broeke, M. R., van Meijgaard, E., van de Berg, W. J., Box, J. E., and Steffen, K.: Climate of the Greenland ice sheet using a high-resolution climate model - Part 1: Evaluation, The Cryosphere, 4, 511-527, https://doi.org/10.5194/tc-4511-2010, 2010.

Fausto, R. S., van As, D., Box, J. E., Colgan, W., Langen, P. L., and Mottram, R. H.: The implication of nonradiative energy fluxes dominating Greenland ice sheet exceptional ablation area surface melt in 2012, Geophys. Res. Lett., 43, 2649-2658, https://doi.org/10.1002/2016GL067720, 2016.

Fettweis, X., Franco, B., Tedesco, M., van Angelen, J. H., Lenaerts, J. T. M., van den Broeke, M. R., and Galleee, H.: Estimating the Greenland ice sheet surface mass balance contribution to future sea level rise using the regional atmospheric climate model MAR, The Cryosphere, 7, 469-489, https://doi.org/10.5194/tc7-469-2013, 2013.

Fettweis, X., Box, J. E., Agosta, C., Amory, C., Kittel, C., Lang, C., van As, D., Machguth, H., and Gallée, H.: Reconstructions of the 1900-2015 Greenland ice sheet surface mass balance using the regional climate MAR model, The Cryosphere, 11, 1015-1033, https://doi.org/10.5194/tc-11-1015-2017, 2017.
Forster, R. R., Box, J. E., van den Broeke, M. R., Miège, C., Burgess, E. W., van Angelen, J. H., Lenaerts, J. T. M., Koenig, L. S., Paden, J., Lewis, C., Gogineni, S. P., Leuschen, C., and McConnell, J. R.: Extensive liquid meltwater storage in firn within the Greenland ice sheet, Nat. Geosci., 7, 95-98, https://doi.org/10.1038/ngeo2043, 2013.

Hines, K. M. and Bromwich, D. H.: Development and Testing of Polar Weather Research and Forecasting (WRF) Model. Part I: Greenland Ice Sheet Meteorology, Mon. Weather Rev., 136, 1971-1989, https://doi.org/10.1175/2007MWR2112.1, 2008.

Holtslag, A. A. M. and de Bruin, H. A. R.: Applied Modeling of the Nighttime Surface Energy Balance over Land, J. Appl. Meteorol., 27, 689-704, 1988.

Howat, I. M., Negrete, A., and Smith, B. E.: The Greenland Ice Mapping Project (GIMP) land classification and surface elevation data sets, The Cryosphere, 8, 1509-1518, https://doi.org/10.5194/tc-8-1509-2014, 2014.

Kuipers Munneke, P., van den Broeke, M. R., Lenaerts, J. T. M., Flanner, M. G., Gardner, A. S., and van de Berg, W. J.: A new albedo parameterization for use in climate models over the Antarctic ice sheet, J. Geophys. Res., 116, D05114, https://doi.org/10.1029/2010JD015113, 2011.

Lang, C., Fettweis, X., and Erpicum, M.: Stable climate and surface mass balance in Svalbard over 1979-2013 despite the Arctic warming, The Cryosphere, 9, 83-101, https://doi.org/10.5194/tc9-83-2015, 2015.

Langen, P. L., Fausto, R. S., Vandecrux, B., Mottram, R. H., and Box, J. E.: Liquid Water Flow and Retention on the Greenland Ice Sheet in the Regional Climate Model HIRHAM5: Local and Large-Scale Impacts, Front. Earth Sci., 4, 110, https://doi.org/10.3389/feart.2016.00110, 2017.

Lenaerts, J. T. M., van den Broeke, M. R., Déry, S. J., van Meijgaard, E., van de Berg, W. J., Palm, S. P., and Rodrigo, J. S.: Modeling drifting snow in Antarctica with a regional climate model: 1. Methods and model evaluation, J. Geophys. Res., 117, D05108, https://doi.org/10.1029/2011JD016145, 2012.

Lenaerts, J. T. M., Ligtenberg, S. R. M., Medley, B., van de Berg, W. J., Konrad, H., Nicolas, J. P., van Wessem, J. M., Trusel, L. D., Mulvaney, R., Tuckwell, R. J., Hogg, A. E., and Thomas, E. R.: Climate and surface mass balance of coastal West Antarctica resolved by regional climate modelling, Ann. Glaciol., 59, 29-41, https://doi.org/10.1017/aog.2017.42, 2017.

Ligtenberg, S. R. M., Helsen, M. M., and van den Broeke, M. R.: An improved semi-empirical model for the densification of Antarctic firn, The Cryosphere, 5, 809-819, https://doi.org/10.5194/tc-5809-2011, 2011.

Machguth, H., MacFerrin, M., van As, D., Box, J. E., Charalampidis, C., Colgan, W., Fausto, R. S., Meijer, H. A. J., MosleyThompson, E., and van de Wal, R. S. W.: Greenland meltwater storage in firn limited by near-surface ice formation, Nat. Clim. Change, 6, 390-395, https://doi.org/10.1038/NCLIMATE2899, 2016 a.

Machguth, H., Thomsen, H. H., Weidick, A., Ahlstrøm, A. P., Abermann, J., Andersen, M. L., Andersen, S. B., Bjørk, A. A., Box, J. E., Braithwaite, R. J., Bøggild, C. E., Citterio, M., Clement, P., Colgan, W., Fausto, R. S., Gleie, K., Gubler, S., Hasholt, B., Hynek, B., Knudsen, N. T., Larsen, S. H., Merild, S. H., Oerlemans, J., Oerter, H., Olesen, O. B., Smeets, C. J. P. P., Steffen, K., Stober, M., Sugiyama, S., van As, D., van den Broeke, M. R., 
and van de Wal, R. S. W.: Greenland surface mass-balance observations from the ice-sheet ablation area and local glaciers, J. Glaciol., 62, 861-887, https://doi.org/10.1017/jog.2016.75, 2016 b.

Mottram, R., Nielsen, K. P., Gleeson, E., and Yang, X.: Modelling Glaciers in the HARMONIE-AROME NWP model, Adv. Sci. Res., 14, 323-334, https://doi.org/10.5194/asr-14-323-2017, 2017.

Niwano, M., Aoki, T., Hashimoto, A., Matoba, S., Yamaguchi, S., Tanikawa, T., Fujita, K., Tsushima, A., Iizuka, Y., Shimada, R., and Hori, M.: NHM-SMAP: spatially and temporally high-resolution nonhydrostatic atmospheric model coupled with detailed snow process model for Greenland Ice Sheet, The Cryosphere, 12, 635-655, https://doi.org/10.5194/tc12-635-2018, 2018.

Noël, B., van de Berg, W. J., van Meijgaard, E., Kuipers Munneke, P., van de Wal, R. S. W., and van den Broeke, M. R.: Evaluation of the updated regional climate model RACMO2.3: summer snowfall impact on the Greenland Ice Sheet, The Cryosphere, 9, 1831-1844, https://doi.org/10.5194/tc-9-1831-2015, 2015.

Noël, B., van de Berg, W. J., Machguth, H., Lhermitte, S., Howat, I., Fettweis, X., and van den Broeke, M. R.: A daily, $1 \mathrm{~km}$ resolution data set of downscaled Greenland ice sheet surface mass balance (1958-2015), The Cryosphere, 10, 2361-2377, https://doi.org/10.5194/tc-10-2361-2016, 2016.

Noël, B., van de Berg, W. J., van Wessem, J. M., van Meijgaard, E., van As, D., Lenaerts, J. T. M., Lhermitte, S., Kuipers Munneke, P., Smeets, C. J. P. P., van Ulft, L. H., van de Wal, R. S. W., and van den Broeke, M. R.: Modelling the climate and surface mass balance of polar ice sheets using RACMO2 Part 1: Greenland (1958-2016), The Cryosphere, 12, 811-831, https://doi.org/10.5194/tc-12-811-2018, 2018.

Noël, B., van de Berg, W. J., Lhermitte, S., and van den Broeke, M. R.: Rapid ablation zone expansion amplifies north Greenland mass loss, Sci. Adv., 5, eaaw0123, https://doi.org/10.1126/sciadv.aaw0123, 2019.

Pandolfo, J. P.: Wind and Temperature Profiles for Constant-flux Boundary Layer in Lapse Conditions with a Variable Eddy Conductivity to Eddy Viscosity Ratio, J. Atmos. Sci., 23, 495-502, 1966.

Smeets, C. J. P. P. and van den Broeke, M. R.: Temporal and Spatial Variations of the Aerodynamic Roughness Length in the Ablation Zone of the Greenland Ice Sheet, Bound.-Lay. Meteorol., 128, 315-338, https://doi.org/10.1007/s10546-008-9291-0, 2008a.

Smeets, C. J. P. P. and van den Broeke, M. R.: The Parameterisation of Scalar Transfer over Rough Ice, Bound.-Lay. Meteorol., 128, 339-355, https://doi.org/10.1007/s10546-008-9292-z, 2008b.

Tiedtke, M.: A Comprehensive Mass Flux Scheme for Cumulus Parameterization in Large-Scale Models, Mon. Weather Rev., 117, 1779-1800, 1989.

Undén, P., Rontu, L., Järvinen, H., Lynch, P., Calvo, J., Cats, G., Cuxart, J., Eerola, K., Fortelius, C., Garcia-Moya, J. A., Jones, C., Lenderlink, G., McDonald, A., McGrath, R., Navascues, B., Nielsen, N. W., Ødegaard, V., Rodriguez, E., Rummukainen, M., Rõõm, R., Sattler, K., Sass, B. H., SavijŁärvi, H., Wichers Schreur, B., Sigg, R., The, H., and Tijm, A.: The High Resolution Limited Area Model, Hirlam-5 scientific documentation,
Swedish Meteorological and Hydrological Institute, Norrköping, Sweden, 2002.

van Angelen, J. H., Lenaerts, J. T. M., Lhermitte, S., Fettweis, X., Kuipers Munneke, P., van den Broeke, M. R., van Meijgaard, E., and Smeets, C. J. P. P.: Sensitivity of Greenland Ice Sheet surface mass balance to surface albedo parameterization: a study with a regional climate model, The Cryosphere, 6, 1175-1186, https://doi.org/10.5194/tc-6-1175-2012, 2012.

van Angelen, J. H., Lenaerts, J. T. M., van den Broeke, M. R., Fettweis, X., and van Meijgaard, E.: Rapid loss of firn pore space accelerates 21 st century Greenland mass loss, Geophys. Res. Lett., 40, 2109-2113, https://doi.org/10.1002/grl.50490, 2013.

Van de Berg, W. J., Van Meijgaard, E., and Van Ulft, L.: The added value of high resolution in estimating the surface mass balance in southern Greenland, Zenodo, https://doi.org/10.5281/zenodo.3568129, 2019.

van den Broeke, M. R.: Depth and Density of the Antarctic Firn Layer, Arct. Antarct. Alp. Res., 40, 432-438, 2008.

van den Broeke, M. R., Enderlin, E. M., Howat, I. M., Kuipers Munneke, P., Noël, B. P. Y., van de Berg, W. J., van Meijgaard, E., and Wouters, B.: On the recent contribution of the Greenland ice sheet to sea level change, The Cryosphere, 10, 1933-1946, https://doi.org/10.5194/tc-10-1933-2016, 2016.

van den Broeke, M. R., Box, J. E., Fettweis, X., Hanna, E., Noël, B. P. Y., Tedesco, M., van As, D., van de Berg, W. J., and van Kampenhout, L.: Greenland ice sheet surface mass loss: recent developments in observation and modelling, Current Climate Change Reports, 3, 345-456, https://doi.org/10.1007/s40641-017-00848, 2017.

van Kampenhout, L., Rhoades, A. M., Herrington, A. R., Zarzycki, C. M., Lenaerts, J. T. M., Sacks, W. J., and van den Broeke, M. R.: Regional grid refinement in an Earth system model: impacts on the simulated Greenland surface mass balance, The Cryosphere, 13, 1547-1564, https://doi.org/10.5194/tc-13-15472019, 2019.

Van Tricht, K., Lhermitte, S., Lenaerts, J. T. M., Gorodetskaya, I. V., L'Ecuyer, T. S., Noël, B., van den Broeke, M. R., Turner, D. D., and van Lipzig, N. P. M.: Clouds enhance Greenland ice sheet meltwater runoff, Nat. Commun., 7, 10266, https://doi.org/10.1038/ncomms10266, 2016.

Vaughan, D. G., Comiso, J. C., Allison, I., Carrasco, J., Kaser, G., Kwok, R., Mote, P., Murray, T., Paul, F., Ren, J., Rignot, E., Solomina, O., Steffen, K., and Zhang, T.: Climate Change 2013: The Physical Science Basis. Contribution of Working Group 1 to the Fifth Assessment Report of the Intergovernmental Panel on Climate Change, chap. Observations: Cryosphere, Cambridge University Press, 2013.

Vizcaíno, M., Lipscomb, W. H., Sacks, W. J., van Angelen, J. H., Wouters, B., and van den Broeke, M. R.: Greenland Surface Mass Balance as Simulated by the Community Earth System Model. Part I: Model Evaluation and 1850-2005 Results, J. Climate, 26, 7793-7812, 2013. 